NBER WORKING PAPER SERIES

\title{
GEOGRAPHICAL DISTRIBUTION OF EMERGENCY DEPARTMENT CLOSURES AND CONSEQUENCES ON HEART ATTACK PATIENTS
}

\author{
Yu-Chu Shen \\ Renee Y. Hsia \\ Working Paper 22861 \\ http://www.nber.org/papers/w22861 \\ NATIONAL BUREAU OF ECONOMIC RESEARCH \\ 1050 Massachusetts Avenue \\ Cambridge, MA 02138 \\ November 2016
}

This research was supported by the National Heart, Lung, and Blood Institute of the National Institutes of Health under Grant Award Numbers R01HL134182, and the American Heart Association. We would like to thank Jean Roth, Sarah Sabbagh and Nandita Sarkar for excellent research support, and seminar participants at Stanford and UCSF for helpful comments. The views expressed herein are those of the authors and do not necessarily reflect the views of the National Bureau of Economic Research.

NBER working papers are circulated for discussion and comment purposes. They have not been peer-reviewed or been subject to the review by the NBER Board of Directors that accompanies official NBER publications.

(C) 2016 by Yu-Chu Shen and Renee Y. Hsia. All rights reserved. Short sections of text, not to exceed two paragraphs, may be quoted without explicit permission provided that full credit, including ( $)$ notice, is given to the source. 
Geographical Distribution of Emergency Department Closures and Consequences on Heart Attack Patients

Yu-Chu Shen and Renee Y. Hsia

NBER Working Paper No. 22861

November 2016

JEL No. I11,I14

\begin{abstract}
We develop a conceptual framework and empirically investigate how a permanent emergency department (ED) closure affects patients with acute myocardial infarction (AMI). We first document that large increases in driving time to closest ED are more likely to happen in lowincome communities and communities that had fewer medical resources at baseline. Then using a difference-in-differences design, we estimate the effect of an ED closure on access to cardiac care technology, treatment, and health outcomes among Medicare patients with AMI who lived in 24,567 ZIP codes that experienced no change, an increase of $<10$ minutes, 10 to $<30$ minutes, and 30 minutes in driving time to their closest ED. Overall, access to cardiac care declined in all communities experiencing a closure, with access to a coronary care unit decreasing by 18.64 percentage points (95\% CI -30.15, -7.12) for those experiencing 30-minute increase in driving time. Even after controlling for access to technology and treatment, patients with the longest delays experienced a $6.58(95 \%$ CI $2.49,10.68)$ and $6.52(95 \%$ CI $1.69,11.35)$ percentage point increase in 90-day and 1-year mortality, respectively, compared with those not experiencing changes in distance. Our results also suggest that the predominant mechanism behind the mortality increase appeared to be time delay as opposed to availability of specialized cardiac treatment.
\end{abstract}

Yu-Chu Shen

Graduate School of Business and Public Policy

Naval Postgraduate School

555 Dyer Road

Monterey, CA 93943

and NBER

yshen@nps.edu

Renee Y. Hsia

SFGH Medical Center

1001 Potrero Avenue

San Francisco, CA 94110

Renee.Hsia@emergency.ucsf.edu 


\section{Introduction}

Emergency departments (ED) play a critical part in the U.S. health care system. They serve as the first and last resort for those who need immediate care as well as those without access to regular care, and they play a key role in disaster response (Institute of Medicine 2006a). Within the past two decades, the annual number of ED visits increased by over $40 \%$, but the number of EDs decreased by 11\% (AHA 2015), with an increasing proportion of the remaining EDs considered “safety-net” EDs (Tang et al. 2010). This shift has resulted in great concern about the availability of emergency care and the healthcare system's ability to provide accessible care (Hsia et al. 2012b; Institute of Medicine 2006b).

The closure of an ED can have a profound effect on a community. On the one hand, prior literature has documented the adverse effects of ED closures, which include an increase in ED travel distance (Hsia et al. 2012a), higher mortality rates (Liu, Srebotnjak, and Hsia 2014), and an increase in crowding and ambulance diversion (Sun et al. 2006). On the other hand, it has been posited that closures of EDs or hospitals could improve acute care by removing poorperformers from the market (Evans 2015); that is, even if people must travel further, they would receive superior care (Fleming et al. 1995). Moreover, permanent closure of a local ED could have an amplified effect for patients experiencing time-sensitive illnesses requiring prompt intervention, such as acute myocardial infarction (AMI).

While concerns about the potential adverse effects of ED closure remain at large, little systematic empirical evidence investigates the effect of ED closure on patient care and health outcomes at the population level. The closest study examined changes in mortality rates among Medicare AMI patients between 1995 and 2005, and found that communities that experienced an ED shut down and large increases in driving time to their next available ED had substantial 
higher mortality rates; however, the effects dissipated after a few years (Shen and Hsia 2012).

In this study, using nationally representative data, we expand upon this previous work and present a comprehensive framework that explores the mechanisms through which permanent ED closure affects patient access, treatment, and health outcomes in a community. Proper identification of these mechanisms allows policymakers to identify high-risk communities that might need targeted interventions and implement evidence based solutions that improve overall population health. Our research objectives are two-fold. In the first part, we document the geographical distribution of ED closures and explore differences in communities where ED closures occurred. Second, based on the conceptual framework developed below, we compare changes in access to cardiac technology (availability of catheterization lab, cardiac care unit, and cardiac surgery capacity), treatment received (PTCA and thrombolytic therapy), and health outcomes (30-day, 90-day, and 1-year mortality) among Medicare AMI patients whose communities experience varying degrees of driving time increases to their next available ED when the closest ED to the community shuts down, relative to patients from communities that do not experience any permanent ED closure.

\section{Conceptual framework}

Figure 1 lays out potential paths through which patient care and outcomes could be affected when the closest ED to the community shuts down. First, patients would have to travel further to the next available ED (path A). Consequently, the time delays could result in a more severe infarction, leading to worse health outcomes and patients potentially requiring more intensive treatment (path A-1). Indirectly, the time delays could result in delayed or reduced access to cardiac technology and likelihood of treatment (path A-2), which, in turn, could lead to 
poorer health outcomes. Under this framework, time delays have an unambiguous effect on health outcomes, but an ambiguous effect on treatment rate. Our empirical models seek to tease out these two competing effects of time delay on treatment rate.

Second, if an ED shuts down in a community, patients would have to redistribute to remaining operating EDs that might not have the same capabilities as the closed ED (path B). If more patients redistributed to hospitals with better resources (either cardiac or non-cardiac resources), we might expect to see improved health outcomes (or that access to better hospitals would mitigate the adverse effects caused by time delays). On the other hand, if more patients redistributed to hospitals with fewer resources, we would expect to see worse health outcomes given the same amount of time delay.

Lastly, the relative importance between path A and B (i.e., between time delay and patient redistribution) would likely depend on the amount of time delay caused by the ED shutdown. In densely populated communities, the next available ED might only be a few minutes away. We hypothesized that in those communities, time delays would not play a major role in affecting patient welfare. However, in rural areas where the next available ED might be more than 30 minutes away, time delays could become a critical factor. Our empirical analysis investigates the interactions between these two paths.

\section{Data and Variable Definitions}

We obtained patient data from 100\% Medicare Provider Analysis and Review (MedPAR) and linked the data with death date (if applicable) for years 2001-2011. These admission records contain relevant diagnostic, comorbid and procedural information, as well as patient demographics, including location (as identified by ZIP code). We further linked them with the 
Healthcare Provider Cost Reporting Information System and American Hospital Association annual surveys to obtain additional hospital-level information.

We identified the physical address and availability of the ED for each hospital using the AHA annual survey between 2001 and 2013. To minimize reporting errors, we used California Office of Statewide Health Policy and Development (OSHPD) facility data, an administrative database, to verify ED status for California hospitals. In order to identify the closest ED for each patient's community, we obtained longitude and latitude coordinates of a patient's ZIP code geographical center using Census data, and longitude and latitude coordinates of hospitals’ physical address or heliport from prior work (Horwitz and Nichols 2009).

\section{Patient Population}

We identified AMI patients by extracting records with $410 . \mathrm{x} 0$ or $410 . \mathrm{x} 1$ as the principal diagnosis code. Following prior work (McClellan, McNeil, and Newhouse 1994; Shen and Hsia 2012; Shen and Hsia 2015), we excluded patients who had prior AMI admission within the past 12 months to minimize selection bias. As done in previous studies (Shen and Hsia 2015), we excluded patients who did not incur any ED expenses during their inpatient stay (since admission to the ED is the relevant population) ${ }^{1}$, and those who were admitted to hospitals more than 100 miles away from their mailing ZIP codes. To minimize estimation noise, we also excluded patients from communities that experienced multiple changes in driving time to their closest ED. Finally, we excluded ZIP codes that do not have patients both before and after the access change occurred. The final sample of the study included a total of 1.35 million patients from 2001-2011,

\footnotetext{
${ }^{1}$ Before 2006, we could identify admission from emergency department directly from MedPAR records using source of admission as the criteria. Starting 2006, the data field was removed from MedPAR but ED expense is available for all years. In order to have consistency for the entire study period, we use ED expense as a proxy for admission through ED.
} 
with annual number ranges from 107,000 to 134,000 patients.

\section{Defining Access, Treatment, and Mortality Outcomes}

We examined three sets of outcomes. First, we examined whether a patient was admitted to hospitals with the following cardiac technology: catheterization labs, cardiac care units (CCUs), and cardiac surgery capacity (CABG). Second, we examined whether a patient received the following treatments: percutaneous transluminal coronary angioplasty (PTCA), thrombolytic therapy, and coronary artery bypass surgery (CABG). While a certain degree of overlap between the concept of treatment received and access to technology exists (for example, a person receiving catheterization would have to be admitted to a hospital with catheterization capacity), they both capture different pathways by which ED closure can affect patient outcomes as described in our conceptual framework. Lastly, we examined whether a patient died within 30day, 90-day, and 1-year from the initial admission date.

\section{Defining ED availability for each year}

Our key variables of interest included whether a patient's community experienced an ED closure and how far a patient from such a community had to travel to reach the next available ED. To quantify the ED access change, we identified ED operation for each hospital in a given year in the following steps. First, we used a combination of AHA and OSHPD data to identify the ED service line for each hospital. Second, due to possible reporting errors in the AHA and OSHPD data, we imputed missing or incorrect values using adjacent years (Hsia, Kellermann, and Shen 2011; Shen 2008). Third, we followed prior literature in defining ED availability for each hospital (Baker and Phibbs 2002; Hsia et al. 2011; Shen 2008). Opening year was defined 
as the first year of the first consecutive pair of years in which a hospital reports operation of an ED. Closure year was defined as the year after the last year in which our data show the hospital operated an ED.

\section{Defining ED access change categories}

We identified the closest ED to a given community by computing actual driving time between each patient-hospital pair using Google Maps queries based on the pair’s geographical coordinates (via Google maps API key and automation software from Stata (Ozimek and Miles 2011)). For each year, hospitals with an operating ED were designated the closest ED for that community if the driving time was the shortest for that patient-hospital pair. One drawback of Google Maps is that the driving time is subject to real time traffic, which can be volatile. To minimize errors in this estimation, we restricted our sample to communities where the same ED was identified as the closest ED based on driving time and driving distance (which excluded $0.79 \%$ of our patient sample).

Once we identified the closest ED for each community for each year, we evaluated yearto-year change and classified the communities according to whether the driving time between a community and the nearest ED met the following conditions between 2001 and 2011: (1) did not increase (the control group); (2) increased by less than 10 minutes; or (3) increased by 10-30 minutes; and (4) increased by more than 30 minutes. The thresholds for the three treatment groups, based from prior work (Shen and Hsia 2012), reflects the importance of timely care. The three driving time increase categories allowed us to investigate the extent to which time delays affect patient outcomes. We excluded patients from communities that experienced multiple changes in ED access during the study period ( $0.12 \%$ of the patient sample). 


\section{Methods and Results}

\section{Geographical Distribution of ED Closures and Community Characteristics}

Between 2001 and 2013, the number of operating EDs in general acute short-term stay hospitals decreased, from 4,296 in 2001 to 3,875 in 2013 (Figure 2). Using the ED access change definition described above and population count from the 2010 Census, Figure 2 also shows the cumulative percent population in communities affected by ED closure. As of 2013, $15 \%$ of the population had experienced ED closure in their communities sometime during this period. Figure 3 shows geographical distribution of communities that experienced changes in ED access. While over $80 \%$ of the communities maintain the same driving distance to their closest ED, closures happened all across the U.S., and was not concentrated in only a few states. We further explored whether there were systematic differences between the control and each of the three treatment communities during the pre-change period by implementing three sets of pairwise comparison using logistic regression. In the first set, we included communities that did not experience any change in ED access (control group) and communities that experienced $<10$ min increase in driving time (treatment) during our study period, giving the dependent variable a value of 1 if the community belonged to the treatment group. The independent variables included community population characteristics, hospital market characteristics within 15-mile radius, and baseline mortality level. Specifically, we included a community’s distribution of median family income, racial or ethnic minorities (black, Hispanic), foreign-born populations, and elderly residents ( $\geq 65$ years old). For ease of interpretation, we divided all communities into three categories based on the distribution of a given subpopulation (i.e., low, median, and high share). Hospital market characteristics included an indicator for 
whether the 15-mile radius market was ranked in top tertile of hospital HHI distribution, whether the community's hospital market included teaching, for-profit, government hospitals, and whether the community had access to catheterization lab, cardiac care unit, and cardiac surgery capacity within 15-mile radius. Lastly, to document possible differences in baseline mortality rate, we used the National Death Index and included indicators for communities that were ranked in the top tertile of deaths per capita due to AMI, accidents, and all deaths. In the next 2 sets of analysis, we repeated the same analysis but change the treatment group to communities where driving time to closest ED increased by 10-30 or $\geq 30$ minutes, respectively.

The pairwise comparison in Table 1 reveals several insights. First, large increases in driving time were more likely to happen in low-income communities (those that ranked in the bottom $1 / 3$ of median family income) and communities with a low share of black population. Compared to the reference community, a low-income community was 1.6 and 9.53 times more likely to experience 10-30 minute and $\geq 30$ minutes increase in driving time, respectively. Second, communities that experienced a $\geq 30$ minutes increase in driving time to their next available ED were more likely to have fewer hospitals within its 15-mile radius; specifically, they were 4.57 times more likely to be in a market that ranked in the top $1 / 3$ of the hospital HHI distribution. Additionally, there were virtually no teaching hospitals among those communities. Third, baseline access to catheterization lab was low in communities that experienced large increases in driving time. The odds of having access to catheterization lab within 15-mile radius were 0.65 and 0.29 , respectively, for communities that experienced 10 -30 minute and $\geq 30$ minute increase in driving time. There did not appear to be differences in AMI and accident death rates (conditions that might be sensitive to immediate access to a hospital) between the control and treatment communities. As we explain below, the multivariate models that 
incorporated community fixed effects controlled for these baseline differences across communities.

Estimating Effects of ED Driving Time Change on Access, Treatment, and Outcomes

Using a difference-in-differences design, we estimated the following equation:

$$
Y_{i j t}=\alpha_{t}+\beta_{1} \operatorname{Inc10}_{j t}+\beta_{2} \text { Inc10-30 } 0_{j t}+\beta_{3} I_{n c g t 3 o}+\beta_{4} X_{i j t}+\beta_{5} H_{i t}+Z_{j}+\epsilon_{i j t}
$$

where

$Y_{i j t}=$ access, treatment, and health outcomes of patient $i$ in community $j$ in year $t$;

$I n c 10_{j t}=1$ for community $j$ on and after year $t$ when time to closest ED increased by $<10$ min;

Inc10 $30_{j t}=1$ for community $j$ on and after year $t$ when time to closest ED increased by 10-30 min;

Incgt $30_{j t}=1$ for community $j$ on and after year $t$ when time to closest ED increased by $\geq 30$ min;

$X_{i j t}=$ demographic and comorbid conditions of patient $i$ in community $j$ in year $t$;

$H_{i t}=$ hospital characteristics of patient $i$ 's admitting hospital;

$Z_{j}=$ ZIP codes fixed effects;

$\alpha_{t}=$ year dummies.

Under this set up, our control group comprised of patients who lived in ZIP codes with no increase in driving time to their closest ED. We applied a linear probability model with ZIP code fixed effects to estimate the effect of increased driving time to the nearest ED on patient outcomes (access, treatment received, and mortality), while controlling for time-varying characteristics. They key variables of interest consisted of the three ED access change categories defined above. The ZIP codes fixed-effects allowed us to remove time-invariant differences in underlying population, health care resources and economic environment across communities that 
experienced different degrees of ED access change during the study period. In essence, we compared changes in outcomes from patients in affected communities before and after an ED closure occurred to the change in outcomes during the same period from patients in communities that did not experience an ED closure.

In all models, we controlled for patient demographics, including 5-year age groups, gender, minority and other non-white race, urban, as well as 22 comorbid measures based on prior work (Elixhauser et al. 1998). We also included year indicators to capture the macro trends and took into account the hospital organizational characteristics of the admitting hospital, such as hospital ownership (for-profit, government), teaching status (defined as resident-to-bed ratio exceeds 0.25 ), case mix index to capture overall severity of the underlying patient population, size (measured by log transformed total inpatient discharges), occupancy rate, system membership, and Herfindahl index to capture the competitiveness of the hospital market within a 15-mile radius ( 0 being perfectly competitive and 1 being monopoly).

We applied this main model to all outcomes (access, treatment, and health outcomes). The results on access allow us to directly assess whether ED closure redistributed patients to hospitals with better or worse cardiac capacity. Coefficients from the three ED access change indicators effectively capture the "net effect" of time delays as the result of ED closure (without differentiating the mechanisms) for treatment and health outcomes. In the second model, we control for access (by including indicators to capture whether admitting hospital had cardiac care technology) when estimating treatment outcomes. Comparison between results from Models 1 and 2 allows us to decipher whether an ED closure affects treatment patterns through path A-1 or A-2. In the third model, we controlled for access and treatment when estimating health outcomes. Model 3 allows us to isolate the direct effect of time delays on health outcomes (i.e., 
path A-1).

Our final patient sample consisted of 1.35 million Medicare patients with AMI from 24,567 ZIP code areas whose admission dates were between 2001 and 2011. Table 2 summarizes the descriptive statistics of the population. In general, patient characteristics, such as age, sex, race, and comorbid conditions, did not differ much across groups with different increases in driving times. However, mirroring differences at the community level shown in Tale 1 , patients in communities with $\mathrm{a} \geq 30$ minute-increase in driving time had a lower probability of being admitted to hospitals with catheterization labs ( $40 \%$ vs. $82 \%$ ) before the ED closure occurred. They had a higher probability of being admitted to government hospitals (31\% vs. $12 \%)$ and lower probability of being admitted to teaching hospitals (1\% vs. 11\%).

Table 3 presents the coefficients of the three ED access change indicators from our main model (Appendix Table 1 shows complete regression results). We did not find that patients redistributed to hospitals with better cardiac care capacity when an ED closure occurred. For example, the percent of patients admitted to hospitals with CCU decreased in all three treatment groups after an ED closure occurred in the community, relative to patients in communities with no ED closure during the same period. Findings showed a particularly striking decrease among patients in communities where the next available ED was more than a 30-minute drive (by 18.64 percentage point, 95\% CI -30.15, -7.12). We had similar findings of decreased admission to hospitals with a catheterization lab and cardiac surgery capacity among patients in communities that faced less than a 30-minute increase in driving time. For communities where patients had to travel 30 minutes or more to reach the next available ED, access to a catheterization lab remained similar after the ED closure occurred.

As described in our methods section, we captured the net effect of time delays when 
examining treatment without controlling for access to cardiac technology. Model 1 showed no associations between treatment rate and increased driving time due to ED closure except for a small decrease in likelihood of thrombolytic therapy in patients with a driving time increase of 10-30 minutes (-0.69 percentage points, CI -1.29, -0.09) (Table 2). However, when we controlled for access to the cardiac technology (Table 4; complete regression results are in Appendix Table 2), we found that PTCA rates increased steadily across the three ED access categories: by 1.99 (CI 0.49, 3.49) in communities with <10 minutes increase in driving time, 2.37 (CI 0.61, 4.13) in communities with 10-30 minutes increase, and 2.67 percentage points (CI -3.42, 8.76, wide CI likely due to small sample size) in communities with at least a 30 minute increase, respectively, relative to patients in communities with no ED closure nearby.

Consistent with the conceptual framework's prediction, we found that a substantial increase in driving time was associated with higher mortality rates. In Model 1 (Table 3), patients whose driving time related to local ED closure increased by $\geq 30$ minutes had a statistically significant increase in 90-day mortality by 6.20 percentage points (CI 1.97, 10.43) and 1-year mortality by 6.00 percentage points (CI $0.78,11.23$ ). To put the magnitude of the mortality rate increases in perspective, the 90 -day mortality rate is $22 \%$ in the reference group. A 6.20 percentage point increase represents a $28 \%$ increase in 90 -day mortality. Patients whose driving time increased by 10-30 minutes had a significant but less pronounced increase in 90-day and 1-year mortality of 1.36 percentage points (CI 0.28, 2.44) and 1.76 percentage points (CI $0.67,2.85)$, respectively. Patients whose driving time increased by less than 10 minutes did not experience higher mortality rates after ED closure occurred in their communities. When we controlled for access and treatment to examine the direct effect of time delays on health outcomes (Table 4), the increase in mortality rate was even greater compared to the unadjusted 
results. Patients who experienced a drive time increase of 30 minutes or more had an increase in 90-day mortality by 6.58 percentage points (CI 2.49, 10.68) (representing a 30\% higher 90-day mortality relative to patients not experience any decline in access), and an increase in 1-year mortality by 6.52 percentage points (CI 1.69, 11.35) (representing a 21\% higher 1-year mortality).

We further investigated whether access to better cardiac care resources might mitigate the adverse effect of time delays on health outcomes. We re-estimated Model 3 by stratifying the sample into those that were admitted to PCI-capable hospitals and to non-PCI hospitals (Table 5). We found that the adverse effect of time delay was more pronounced among patients admitted to non-PCI hospitals compared to patients admitted to PCI-capable hospitals. Specifically, when we restricted the sample to those admitted to non-PCI hospitals, those who had a $\geq 30$ minute increase in driving time due to closure had an increase in 90-day and 1-year mortality by 7.17 percentage points (CI 0.38, 13.97) and 7.83 percentage points (CI 1.40, 14.26), respectively, relative to patients with no increase in driving time to their nearest ED. These percentage point differences represent a $28 \%$ and 21\% increase in 90-day and 1-year mortality, respectively. Among patients admitted to PCI-capable hospitals, we still observed a statistically significant increase in 90-day mortality rate albeit at a smaller magnitude (4.28 percentage points, CI 0.27, 8.29).

\section{Discussion}

In this study, we presented a conceptual framework and empirically explored the type of communities affected by ED closures and how local ED closures can affect patients who require prompt medical interventions. We did not find evidence in support of the concept that an ED 
closure benefits communities by closing down poor performers and redistributing patients to hospitals with better resources. Even in densely populated communities where local ED closure only increased driving time to the next available ED by less than 10 minutes, access to cardiac care technology decreased after the closure occurred.

We found that without controlling for access, the net effect of ED closure on treatment was negligible, as there were virtually no decreases in likelihood for PTCA or thrombolytic treatment when a community experienced a local ED closure. Such finding likely reflects two competing effects of ED closure described in our conceptual framework: time delays might increase the need for more intensive treatment, but at the same time decrease access to cardiac capacity. When we controlled for access to cardiac technology, we found that the rate of PTCA increased as driving time to the next available ED increased, suggesting that time delay is associated with increase medical need for PTCA. An alternative interpretation is that after an ED closure, patients who ended up in PCI-capable hospitals were systematically redistributed to hospitals that had higher propensity to perform PTCA, holding all other factors constant. Our data did not allow us to explicitly differentiate between the two possible explanations. However, if such an alternative interpretation is true, we would expect the magnitude of the treatment rate increase to be similar across the three treatment groups.

Our results suggested that when patients had to drive at least 10 more minutes to their next available ED upon local ED closure, time delay became the dominant mechanism in affecting health outcomes when local ED closure occurred, both directly (as time delays causes more severe infarction) and indirectly through its effect on access and treatment. Consistent with the conceptual framework, we did not find an increase in mortality for patients experiencing a small (less than 10 minutes) increase in driving time, suggesting that a closure of an ED 
relatively close to another ED may not have as serious consequences on a community compared with longer increases in driving time. However, the adverse effect of time delay on mortality rates became evident in communities that experienced 10-30 min increase in driving time, and became substantial in communities that experienced more than 30-minute increase in driving time. The adverse effect did not resolve even after we controlled for access and treatment, suggesting that the time delays likely made the prognosis worse, directly affecting mortality rates. It is also important to note that these affected communities are also the ones that started out with fewer medical resources than the communities that experience no or little change in driving time. Moreover, patients admitted to non-PCI hospitals had substantially greater adverse effects of time delay on health outcomes, suggesting that availability of cardiac care technology might mitigate the adverse effect of time delay. Prior studies have suggested that manageable increases in patient volumes can result in better outcomes for a particular ED and medical facility (Halm, Lee, and Chassin 2002; Kocher et al. 2014; Schull, Vermeulen, and Stukel 2006), and this could counteract any potential modest delays in treatment. We are cautious in this interpretation because we found that a relatively small increase in driving time related to ED closure was associated with noticeable increases in mortality.

This study differed notably from prior studies, as it covered a comprehensive set of outcomes, used real-time data for precise driving times, and covered a more recent study period. We acknowledged that people do not always use the closest ED in their community as their source of care. Rather, our intention was to use changes in driving time to the nearest ED as a proxy for disruption to permanent ED access in the local community. In addition, we evaluated the effect of ED closure as a whole, without differentiating between ED closure as the result of hospital closure or as a result of hospital closing their ED service line, as our goal was to 
evaluate the effect of disruption in ED resources in a community.

We performed a variety of sensitivity analyses to test the robustness of the results. In one robustness check, we limited our patients to those with similar baseline area characteristics; in another, we limited our analysis to communities where the number of hospitals at baseline was comparable to one another. We obtained similar conclusions from all of these sensitivity analyses.

Nonetheless, our study had several limitations. First, our driving time computation was based on longitude and latitude information of ZIP codes’ geographical center as defined by Census. Even though queries from Google Maps allow us to take into account general traffic conditions, mountain roads, and bodies of water, actual driving time to the same ED can be different between two people from the same ZIP code especially in rural communities. Second, we did not account for ED capacity on the day of a patient's visit, which introduced measurement errors in our measure of access change. Third, we could not capture the quality of pre-hospital care; however, no study has shown an association between quality of EMS care and ED availability.

Our findings of increased AMI mortality point to the need for a more careful consideration of the implications of ED closure. The loss of a local ED, particularly in regions with limited options for acute care can exacerbate time-sensitive illnesses other than AMI. Accordingly, prior to closing an ED, more targeted planning to distribute system-level resources is needed.

In particular, changes in ED access could have different consequences for different communities, depending on the baseline medical care resources available. A closure of an ED may not necessarily be detrimental for communities that have other medical care resources 
available within close proximity. However, our data suggest that ED closures are more likely to happen in low-income communities that have worse access to critical cardiac care technology to start with, and that ED closure can potentially have substantial adverse effects on communities with limited resources for acute care.

\section{Conclusions}

Our study showed that patients with AMI whose driving time to the nearest ED after local ED closure increased by 10 minutes or more had a significant increase in mortality. Among those who experienced a closure that resulted in a drive time increase of 30 minutes or more, they experienced a 30\% higher 90-day mortality and 21\% higher 1-year mortality. Increased driving time due to a closure was also associated with an overall decrease in access to cardiac technology in the remaining hospitals. Our findings suggest that permanent ED closure has substantial consequences on patient outcomes, particularly among communities with limited resources for time-sensitive illnesses such as AMI. We find that the predominant mechanism by which patients' outcomes decline is primarily due to time delay, as opposed to changes in availability of treatment. We can conclude that while provision of necessary cardiac technology is one important factor for remaining hospitals, the effects of a time delay due to an ED closure are not easily mitigated. 


\section{References}

AHA. 2015. “Trendwatch Chartbook 2015: Emergency Department Visits, Emergency Department Visits per 1,000 Persons, and Number of Emergency Departments, 1993-2013.” Avalere Health analysis of AHA Annual Survey data, 2013, for community hospitals. US Census Bureau: National and State Population Estimates, July 1, 2013.

Baker, L. and C. Phibbs. 2002. "Managed care, technology adoption, and health care: the adoption of neonatal intensive care.” Rand J Econ 33(3): 524-48.

Elixhauser, A., C. Steiner, D. R. Harris, and R. M. Coffey. 1998. "Comorbidity measures for use with administrative data." Med Care 36(1): 8-27.

Evans, M. 2015. "After a hospital closes, a community's health can improve" [accessed on June 1, 2015]. Available at: http://www.modernhealthcare.com/article/20150509/MAGAZINE/305099964.

Fleming, S. T., H. A. Williamson, Jr., L. L. Hicks, and I. Rife. 1995. "Rural hospital closures and access to services.” Hosp Health Serv Adm 40(2): 247-62.

Halm, E. A., C. Lee, and M. R. Chassin. 2002. "Is volume related to outcome in health care? a systematic review and methodologic critique of the literature.” Ann Intern Med 137(6): 511-20. Horwitz, J. R. and A. Nichols. 2009. "Hospital ownership and medical services: market mix, spillover effects, and nonprofit objectives.” J Health Econ 28(5): 924-37.

Hsia, R. Y., H. K. Kanzaria, T. Srebotnjak, J. Maselli, C. McCulloch, and A. D. Auerbach. 2012a. "Is emergency department closure resulting in increased distance to the nearest emergency department associated with increased inpatient mortality?” Ann Emerg Med 60(6): 707-15.e4.

Hsia, R. Y., A. L. Kellermann, and Y. Shen. 2011. "Factors associated with closures of emergency departments in the United States.” JAMA 305(19): 1978-85.

Hsia, R. Y., T. Srebotnjak, H. K. Kanzaria, C. McCulloch, and A. D. Auerbach. 2012b. "System level health disparities in California emergency departments: minorities and Medicaid patients are at higher risk of losing their EDs.” Ann Emerg Med 59(5): 358-65.

Institute of Medicine. 2006a. "The future of emergency care in the United States health system." Academic Emergency Medicine 13(10): 1081-5.

Institute of Medicine. 2006b. "Hospital-Based Emergency Care: At the Breaking Point.”. Washington, DC: Institute of Medicine.

Kocher, K. E., A. N. Haggins, A. K. Sabbatini, K. Sauser, and A. L. Sharp. 2014. “Emergency department hospitalization volume and mortality in the United States.” Ann Emerg Med 64(5): 446-57.e6.

Liu, C., T. Srebotnjak, and R. Y. Hsia. 2014. "California emergency department closures are associated with increased inpatient mortality at nearby hospitals.” Health Affairs 33(8): 1323-29. McClellan, M., B. J. McNeil, and J. P. Newhouse. 1994. "Does more intensive treatment of acute myocardial infarction in the elderly reduce mortality? Analysis using instrumental variables." JAMA 272(11): 859-66.

Ozimek, A. and D. Miles. 2011. "Stata utilities for geocoding and generating travel time and travel distance information.” Stata J 11(1): 106-19.

Schull, M. J., M. J. Vermeulen, and T. A. Stukel. 2006. “The risk of missed diagnosis of acute myocardial infarction associated with emergency department volume.” Ann Emerg Med 48(6): 647-55. 
Shen, Y.-C. 2008. "Do HMO and its for-profit expansion jeopardize the survival of hospital safety net services?” Health Economics 18(3): 305-20.

Shen, Y. C. and R. Y. Hsia. 2012. "Does decreased access to emergency departments affect patient outcomes? analysis of acute myocardial infarction population 1996-2005." Health Serv Res 47(1 Pt 1): 188-210.

Shen, Y. C. and R. Y. Hsia. 2015. "Ambulance diversion associated with reduced access to cardiac technology and increased one-year mortality.” Health Affairs 34(8): 1273-80.

Sun, B. C., S. A. Mohanty, R. Weiss, R. Tadeo, M. Hasbrouck, W. Koenig, C. Meyer, and S. Asch. 2006. "Effects of hospital closures and hospital characteristics on emergency department ambulance diversion, Los Angeles County, 1998 to 2004.” Ann Emerg Med 47(4): 309-16. Tang, N., J. Stein, R. Y. Hsia, J. H. Maselli, and R. Gonzales. 2010. "Trends and characteristics of US emergency department visits, 1997-2007." JAMA : the journal of the American Medical Association 304(6): 664-70. 
Figure 1. Conceptual framework of effect of permanent ED access disruption on patient outcomes

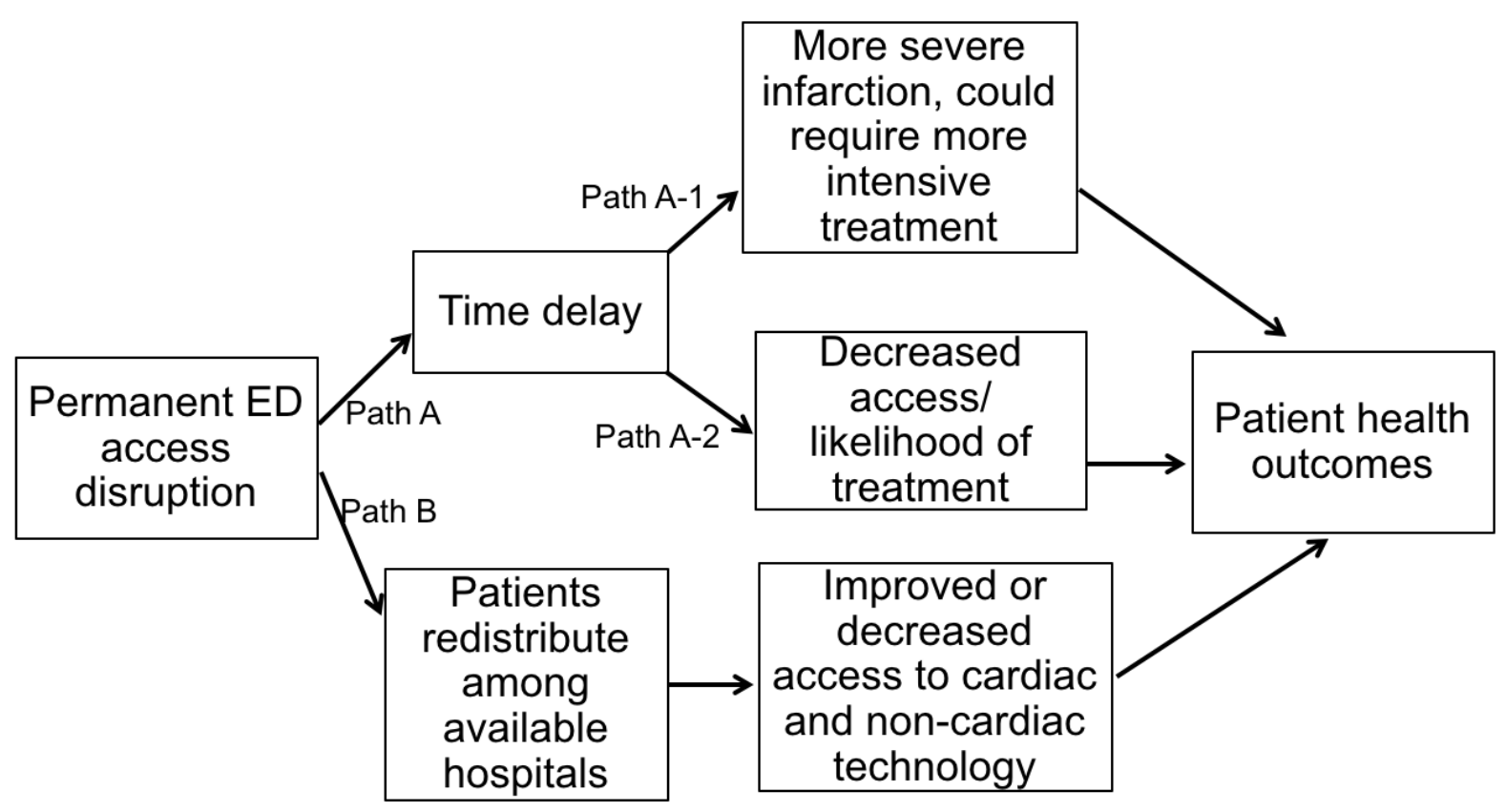


Figure 2. Number of operating EDs and cumulative percent population affected by ED closure

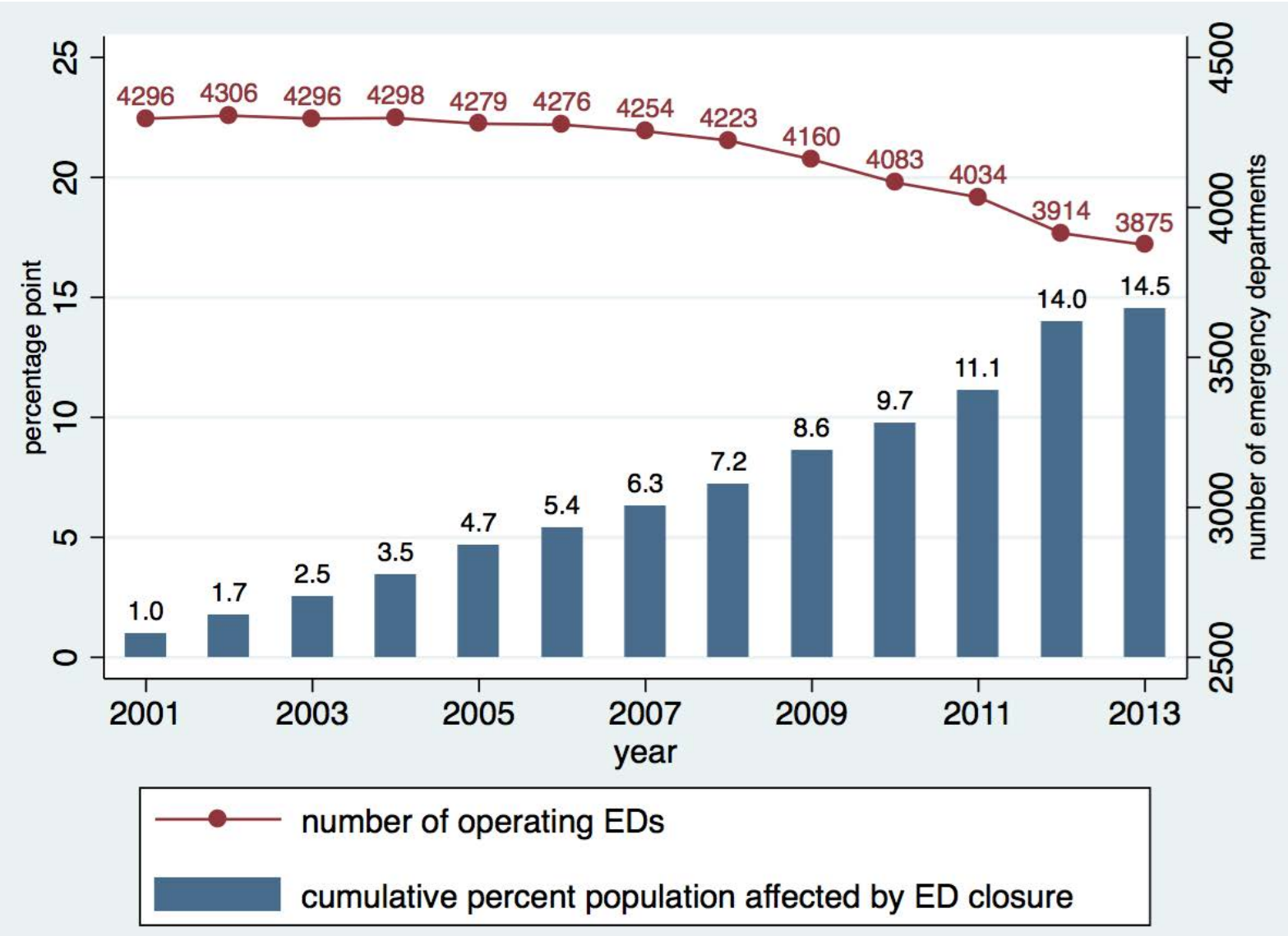


Figure 3. Distribution of ED Access Change between 2001-2011

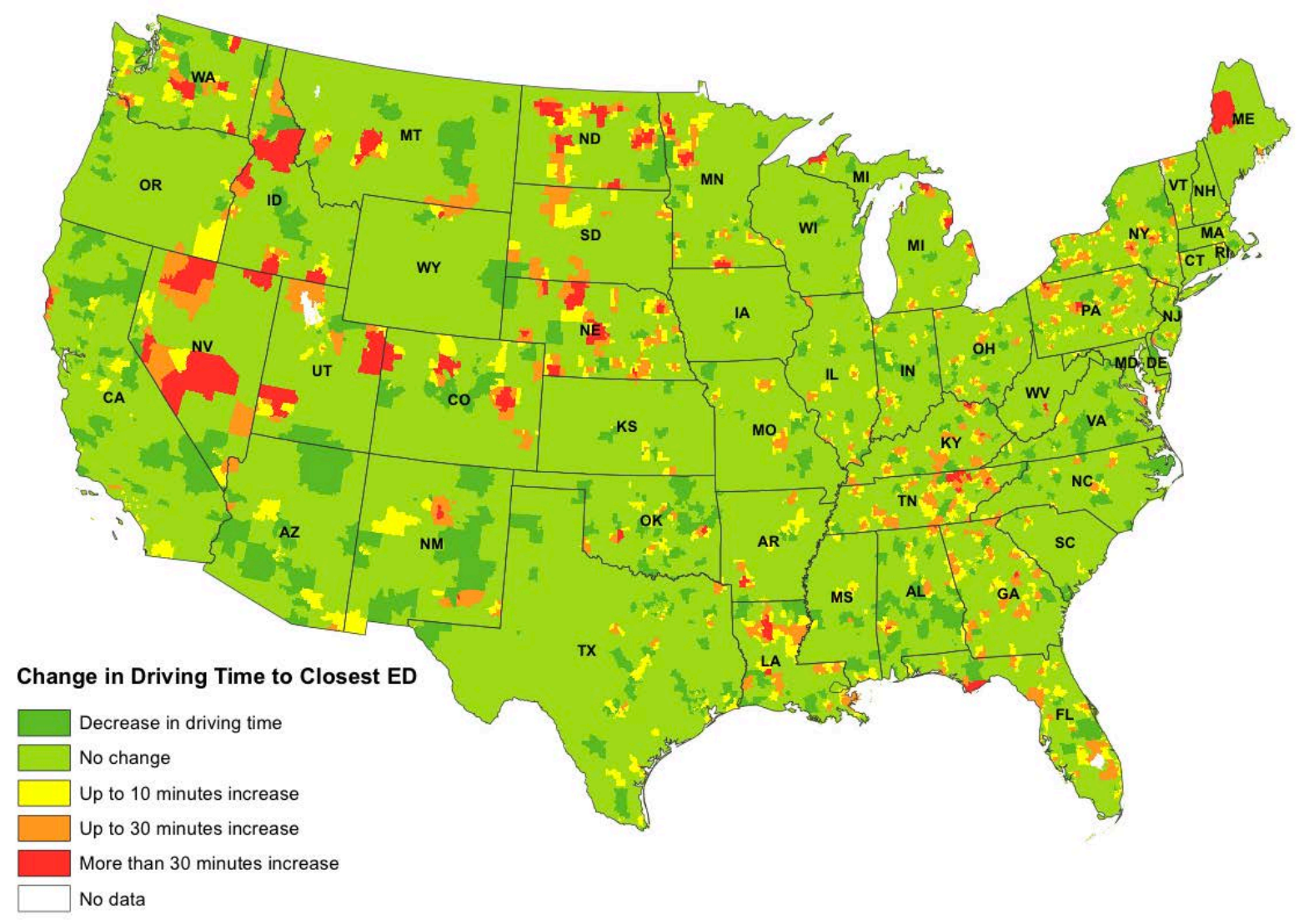


Table 1. Comparing community characteristics between treatment and control communities before ED access change occurred

\begin{tabular}{|c|c|c|c|c|c|c|c|}
\hline & \multirow{2}{*}{$\begin{array}{l}\text { Share in } \\
\text { community } \\
\text { with no } \\
\text { change in } \\
\text { driving time }\end{array}$} & \multicolumn{6}{|c|}{$\begin{array}{l}\text { Odds ratio from logistic regression comparing treatment } \\
\text { community to reference community during pre-treatment period } \\
\text { Driving time increased by: }\end{array}$} \\
\hline & & \multicolumn{2}{|c|}{$<10$ minutes } & \multicolumn{2}{|c|}{ 10-30 minutes } & \multicolumn{2}{|c|}{$>=30$ minutes } \\
\hline \multicolumn{8}{|l|}{ Income Distribution (tertile) } \\
\hline High-income (ref group) & $31 \%$ & 1.00 & {$[1.00,1.00]$} & 1.00 & {$[1.00,1.00]$} & 1.00 & {$[1.00,1.00]$} \\
\hline Medium-income & $33 \%$ & 1.11 & {$[0.90,1.36]$} & 1.33 & {$[0.90,1.97]$} & $3.94+$ & {$[0.86,18.00]$} \\
\hline Low-income & $35 \%$ & $1.25+$ & {$[0.98,1.59]$} & $1.60 *$ & {$[1.03,2.49]$} & $9.53^{\star \star}$ & {$[1.74,52.29]$} \\
\hline \multicolumn{8}{|l|}{ Black population } \\
\hline Low share (ref group) & $34 \%$ & 1.00 & {$[1.00,1.00]$} & 1.00 & {$[1.00,1.00]$} & 1.00 & {$[1.00,1.00]$} \\
\hline Medium share & $33 \%$ & 0.90 & {$[0.72,1.13]$} & 0.85 & {$[0.60,1.20]$} & $0.15^{\star \star}$ & {$[0.05,0.45]$} \\
\hline High share & $33 \%$ & 1.08 & {$[0.87,1.35]$} & 1.11 & {$[0.82,1.50]$} & 0.55 & {$[0.25,1.18]$} \\
\hline \multicolumn{8}{|l|}{ Hispanic population } \\
\hline Low share (ref group) & $34 \%$ & 1.00 & {$[1.00,1.00]$} & 1.00 & {$[1.00,1.00]$} & 1.00 & {$[1.00,1.00]$} \\
\hline Medium share & $34 \%$ & 1.05 & {$[0.83,1.32]$} & 1.14 & {$[0.82,1.59]$} & 1.28 & {$[0.58,2.85]$} \\
\hline High share & $32 \%$ & 1.27 & {$[0.92,1.75]$} & 0.78 & {$[0.47,1.29]$} & 1.05 & {$[0.37,2.99]$} \\
\hline \multicolumn{8}{|l|}{ Foreign-born population } \\
\hline Low share (ref group) & $35 \%$ & 1.00 & {$[1.00,1.00]$} & 1.00 & {$[1.00,1.00]$} & 1.00 & {$[1.00,1.00]$} \\
\hline Medium share & $33 \%$ & 0.97 & {$[0.76,1.23]$} & 1.21 & {$[0.87,1.70]$} & 0.91 & {$[0.35,2.39]$} \\
\hline High share & $32 \%$ & 0.87 & {$[0.62,1.21]$} & $0.59+$ & {$[0.32,1.08]$} & 0.33 & {$[0.07,1.57]$} \\
\hline \multicolumn{8}{|l|}{ Elderly population } \\
\hline Low share (ref group) & $33 \%$ & 1.00 & {$[1.00,1.00]$} & 1.00 & {$[1.00,1.00]$} & 1.00 & {$[1.00,1.00]$} \\
\hline Medium share & $34 \%$ & 0.85 & {$[0.69,1.05]$} & 0.98 & {$[0.64,1.50]$} & 0.42 & {$[0.14,1.24]$} \\
\hline High share & $33 \%$ & 1.17 & {$[0.93,1.46]$} & 1.11 & {$[0.72,1.71]$} & 0.54 & {$[0.19,1.52]$} \\
\hline \multicolumn{8}{|c|}{ Hospital market characteristics within 15-mile radius } \\
\hline $\begin{array}{l}\text { Highly concentrated (Rank top } \\
1 / 3 \text { on } \mathrm{HHI} \text { distribution) }\end{array}$ & $53 \%$ & $0.73^{*}$ & {$[0.57,0.93]$} & $1.54^{*}$ & {$[1.07,2.21]$} & $4.57^{\star \star}$ & {$[2.32,9.01]$} \\
\hline Have teaching hospital & $44 \%$ & $1.26+$ & {$[0.98,1.62]$} & $0.50 * \star$ & {$[0.29,0.84]$} & & \\
\hline Have for-profit hospitals & $45 \%$ & $2.40^{\star *}$ & {$[2.00,2.88]$} & $2.61 * *$ & {$[1.97,3.45]$} & 0.99 & {$[0.41,2.37]$} \\
\hline have government hospitals & $45 \%$ & 1.03 & {$[0.86,1.24]$} & 1.09 & {$[0.85,1.41]$} & 0.67 & {$[0.35,1.25]$} \\
\hline Have catheterization lab & $81 \%$ & 1.05 & {$[0.76,1.46]$} & $0.65^{\star \star}$ & {$[0.48,0.89]$} & $0.29 *$ & {$[0.10,0.79]$} \\
\hline Have cardiac care unit & $76 \%$ & $1.38^{*}$ & {$[1.06,1.82]$} & 1.10 & {$[0.83,1.46]$} & 1.05 & {$[0.62,1.76]$} \\
\hline Have cardiac surgery capacity & $70 \%$ & 0.98 & {$[0.68,1.42]$} & $0.45^{\star *}$ & {$[0.30,0.68]$} & 0.38 & {$[0.06,2.47]$} \\
\hline \multicolumn{8}{|c|}{ Baseline community mortality level } \\
\hline $\begin{array}{l}\text { Rank top } 1 / 3 \text { on deaths due to } \\
\text { AMI } \\
\text { Rank to } 1 / 3 \text { on deaths due to }\end{array}$ & $33 \%$ & 1.07 & {$[0.88,1.30]$} & 1.17 & {$[0.89,1.53]$} & 1.70 & {$[0.83,3.48]$} \\
\hline $\begin{array}{l}\text { accident } \\
\text { Rank top } 1 / 3 \text { on all death }\end{array}$ & $33 \%$ & 1.08 & {$[0.88,1.32]$} & 0.86 & {$[0.63,1.17]$} & 1.77 & {$[0.90,3.51]$} \\
\hline counts & $33 \%$ & 1.12 & {$[0.92,1.37]$} & 1.12 & {$[0.86,1.46]$} & $0.52^{*}$ & {$[0.27,1.00]$} \\
\hline $\mathrm{N}$ & 248138 & & 245107 & & & 239780 & \\
\hline
\end{tabular}

* Logistic regression weighted by community population. Year dummies are included 
Table 2. Descriptive statistics of patient distribution, overall and by ED access change categories

\begin{tabular}{|c|c|c|c|c|c|c|c|c|}
\hline \multirow{4}{*}{$\begin{array}{l}\mathrm{N}(\%) \\
\text { Median driving time to } \\
\text { the closest ED (IQR) } \\
\text { No increase in driving } \\
\text { time }\end{array}$} & \multicolumn{2}{|c|}{$\begin{array}{l}\text { Whole Sample 2001- } \\
\qquad 2011\end{array}$} & \multicolumn{6}{|c|}{$\begin{array}{c}\text { Baseline (pre-ED closure) characteristics } \\
\text { among communities that experienced increased driving time to } \\
\text { nearest ED }\end{array}$} \\
\hline & & & $\begin{array}{l}<10 \mathrm{~min} \\
\text { increas }\end{array}$ & & $\begin{array}{l}10-<30 \mathrm{mi} \\
\text { increase }\end{array}$ & & $\begin{array}{l}>=30 \text { min } \\
\text { increase }\end{array}$ & \\
\hline & 12 & $(7-18)$ & 10 & $(7-15)$ & 10 & $(6-16)$ & 10 & $(4-14)$ \\
\hline & 1334642 & $(92.6 \%)$ & & & & & & \\
\hline$<10$ minute increase & 73094 & $(5.1 \%)$ & & & & & & \\
\hline $10-<30$ min increase & 30753 & $(2.1 \%)$ & & & & & & \\
\hline$>=30$ min increase & 2433 & $(0.2 \%)$ & & & & & & \\
\hline \multicolumn{9}{|l|}{ Patient demographics } \\
\hline Female & 688306 & $(51 \%)$ & 17253 & $(52 \%)$ & 8759 & $(51 \%)$ & 858 & $(55 \%)$ \\
\hline White & 1203859 & $(89 \%)$ & 29224 & $(87 \%)$ & 15205 & $(89 \%)$ & 1410 & $(90 \%)$ \\
\hline $\begin{array}{l}\text { Black } \\
\text { Other non-white }\end{array}$ & 99778 & $(7 \%)$ & 2802 & $(8 \%)$ & 1460 & $(9 \%)$ & 118 & $(8 \%)$ \\
\hline Races & 17477 & $(1 \%)$ & 469 & $(1 \%)$ & 148 & $(1 \%)$ & 14 & $(1 \%)$ \\
\hline Urban communities & 1047391 & $(77 \%)$ & 29892 & $(89 \%)$ & 10626 & $(62 \%)$ & 347 & $(22 \%)$ \\
\hline \multicolumn{9}{|l|}{ Age distribution } \\
\hline $65-69$ & 203118 & $(15 \%)$ & 4632 & $(14 \%)$ & 2563 & $(15 \%)$ & 225 & $(14 \%)$ \\
\hline $70-74$ & 231711 & $(17 \%)$ & 5604 & $(17 \%)$ & 2963 & $(17 \%)$ & 270 & $(17 \%)$ \\
\hline $75-79$ & 259530 & $(19 \%)$ & 6582 & $(20 \%)$ & 3352 & $(20 \%)$ & 260 & $(17 \%)$ \\
\hline $80-84$ & 271215 & $(20 \%)$ & 6821 & $(20 \%)$ & 3518 & $(21 \%)$ & 338 & $(22 \%)$ \\
\hline $85+$ & 388348 & $(29 \%)$ & 9812 & $(29 \%)$ & 4621 & $(27 \%)$ & 469 & $(30 \%)$ \\
\hline \multicolumn{9}{|c|}{ Patient comorbid conditions } \\
\hline \multirow{2}{*}{$\begin{array}{l}\text { Peripheral vascular } \\
\text { disease } \\
\text { Pulmonary Circulation } \\
\text { disorders }\end{array}$} & 112638 & $(8 \%)$ & 2624 & $(8 \%)$ & 1476 & $(9 \%)$ & 138 & $(9 \%)$ \\
\hline & 42791 & $(3 \%)$ & 894 & $(3 \%)$ & 387 & $(2 \%)$ & 32 & $(2 \%)$ \\
\hline Diabetes & 371717 & $(27 \%)$ & 9122 & $(27 \%)$ & 4737 & $(28 \%)$ & 425 & $(27 \%)$ \\
\hline Renal failure & 165765 & $(12 \%)$ & 2908 & $(9 \%)$ & 1469 & $(9 \%)$ & 108 & $(7 \%)$ \\
\hline Liver disease & 6865 & $(1 \%)$ & 173 & $(1 \%)$ & 57 & $(0 \%)$ & 7 & $(0 \%)$ \\
\hline Cancer & 50073 & $(4 \%)$ & 1184 & $(4 \%)$ & 602 & $(4 \%)$ & 68 & $(4 \%)$ \\
\hline Dementia & 50707 & $(4 \%)$ & 1444 & $(4 \%)$ & 731 & $(4 \%)$ & 53 & $(3 \%)$ \\
\hline Valvular disease & 200165 & $(15 \%)$ & 5340 & $(16 \%)$ & 2369 & $(14 \%)$ & 134 & $(9 \%)$ \\
\hline \multirow{2}{*}{$\begin{array}{l}\text { Hypertension } \\
\text { Chronic pulmonary } \\
\text { disease }\end{array}$} & 803711 & $(59 \%)$ & 19119 & $(57 \%)$ & 9664 & $(57 \%)$ & 848 & $(54 \%)$ \\
\hline & 296667 & $(22 \%)$ & 7358 & $(22 \%)$ & 4252 & $(25 \%)$ & 331 & $(21 \%)$ \\
\hline Rheumatoid arthritis & 26231 & $(2 \%)$ & 599 & $(2 \%)$ & 282 & $(2 \%)$ & 44 & $(3 \%)$ \\
\hline Coagulation deficiency & 41225 & $(3 \%)$ & 1037 & $(3 \%)$ & 428 & $(3 \%)$ & 37 & $(2 \%)$ \\
\hline Obesity & 48856 & $(4 \%)$ & 881 & $(3 \%)$ & 518 & $(3 \%)$ & 26 & $(2 \%)$ \\
\hline Substance abuse & 15152 & $(1 \%)$ & 378 & $(1 \%)$ & 185 & $(1 \%)$ & 13 & $(1 \%)$ \\
\hline Depression & 45569 & $(3 \%)$ & 1036 & $(3 \%)$ & 541 & $(3 \%)$ & 58 & $(4 \%)$ \\
\hline Psychosis & 15709 & $(1 \%)$ & 416 & $(1 \%)$ & 172 & $(1 \%)$ & 15 & $(1 \%)$ \\
\hline \multirow{2}{*}{$\begin{array}{l}\text { Hypothyroidism } \\
\text { Paralysis and other } \\
\text { neurological disorder }\end{array}$} & 121491 & $(9 \%)$ & 2830 & $(8 \%)$ & 1400 & $(8 \%)$ & 132 & $(8 \%)$ \\
\hline & 109975 & $(8 \%)$ & 2827 & $(8 \%)$ & 1416 & $(8 \%)$ & 97 & $\begin{array}{r}(6 \%) \\
26\end{array}$ \\
\hline
\end{tabular}




\begin{tabular}{|c|c|c|c|c|c|c|c|c|}
\hline $\begin{array}{l}\text { Chronic Peptic ulcer } \\
\text { disease }\end{array}$ & 509 & $(0 \%)$ & 18 & $(0 \%)$ & 8 & $(0 \%)$ & 1 & $(0 \%)$ \\
\hline $\begin{array}{l}\text { Weight loss } \\
\text { Fluid and electrolyte }\end{array}$ & 25805 & $(2 \%)$ & 520 & $(2 \%)$ & 263 & $(2 \%)$ & 27 & $(2 \%)$ \\
\hline & 258390 & $(19 \%)$ & 6796 & $(20 \%)$ & 3027 & $(18 \%)$ & 292 & $(19 \%)$ \\
\hline and deficiency) & 154478 & $(11 \%)$ & 3865 & $(12 \%)$ & 1884 & $(11 \%)$ & 157 & $(10 \%)$ \\
\hline \multicolumn{9}{|c|}{ Admitting hospital characteristics } \\
\hline Catheterization lab & 1105288 & $(82 \%)$ & 27724 & $(83 \%)$ & 10728 & $(63 \%)$ & 617 & $(40 \%)$ \\
\hline $\begin{array}{l}\text { Cardiac intensive unit } \\
\text { Cardiac surgery }\end{array}$ & 862501 & $(64 \%)$ & 22581 & $(68 \%)$ & 7478 & $(44 \%)$ & 726 & $(46 \%)$ \\
\hline capacity & 761572 & $(56 \%)$ & 20182 & $(60 \%)$ & 6116 & $(36 \%)$ & 351 & $(22 \%)$ \\
\hline For-profit hospitals & 180651 & $(13 \%)$ & 7129 & $(21 \%)$ & 5586 & $(33 \%)$ & 311 & $(20 \%)$ \\
\hline Government hospitals & 157996 & $(12 \%)$ & 2944 & $(9 \%)$ & 2146 & $(13 \%)$ & 485 & $(31 \%)$ \\
\hline Teaching hospitals & 151253 & $(11 \%)$ & 5316 & $(16 \%)$ & 868 & $(5 \%)$ & 14 & $(1 \%)$ \\
\hline $\begin{array}{l}\text { Member of a system } \\
\text { Mean total beds in }\end{array}$ & 859917 & $(64 \%)$ & 23402 & $(70 \%)$ & 10730 & $(63 \%)$ & 797 & $(51 \%)$ \\
\hline $\begin{array}{l}\text { hospital (SD) } \\
\text { Mean occupancy rate }\end{array}$ & 297.11 & $(947.89)$ & 313.09 & $(235.91)$ & 209.23 & $(182.64)$ & 121.48 & $(119.62)$ \\
\hline (SD) & 0.66 & $(0.16)$ & 0.66 & $(0.16)$ & 0.58 & $(0.17)$ & 0.48 & $(0.15)$ \\
\hline Mean $\mathrm{HHI}$ index (SD) & 0.46 & $(0.33)$ & 0.32 & $(0.27)$ & 0.58 & $(0.31)$ & 0.93 & $(0.20)$ \\
\hline $\begin{array}{l}\text { Number of communities } \\
\text { Number of patients }\end{array}$ & $\begin{array}{r}24,567 \\
1,353,922\end{array}$ & & $\begin{array}{r}890 \\
33,451\end{array}$ & & $\begin{array}{r}542 \\
17,017\end{array}$ & & $\begin{array}{r}56 \\
1,562\end{array}$ & \\
\hline
\end{tabular}


Table 3. Regression-adjusted percentage point changes in outcomes relative to patients in communities that experienced no ED closure, based on Model 1 specifications

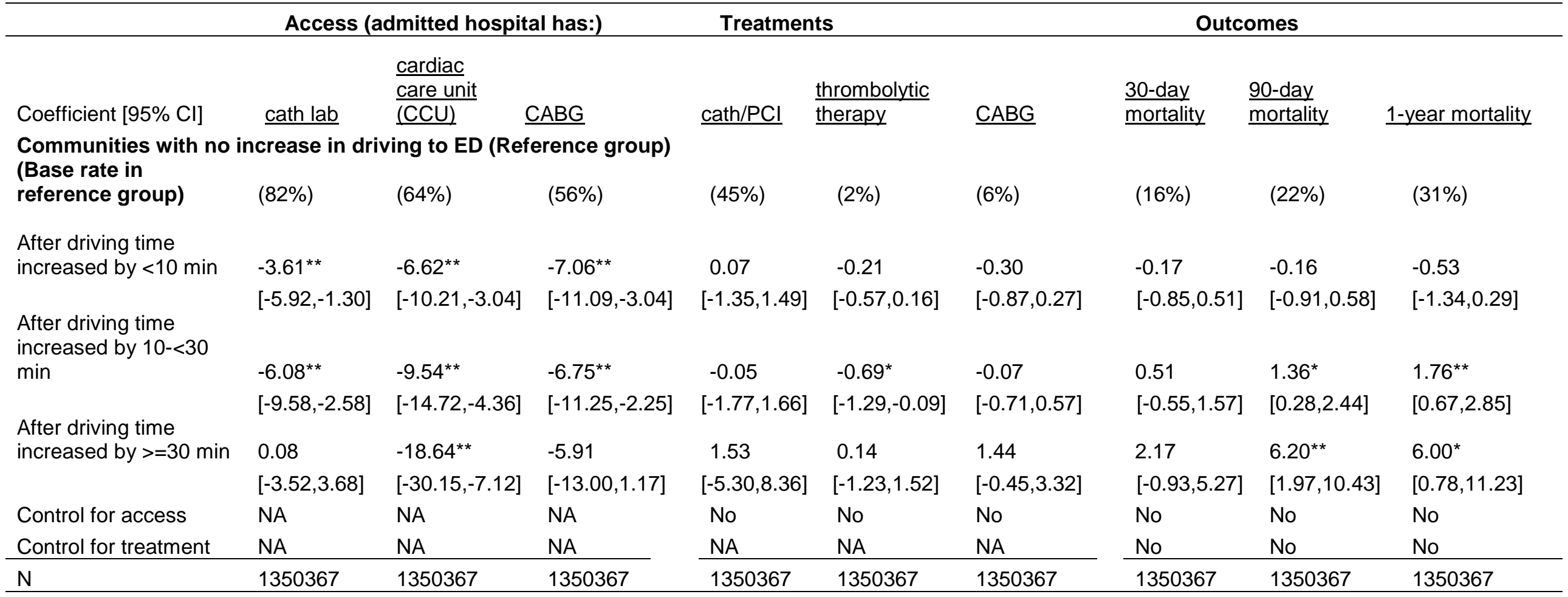

* Driving time to nearest ED Based on Google map queries

** Coefficients represent differences in percentage point compared to the reference group.

Significant at $+p<0.10{ }^{*} \mathrm{p}<0.05{ }^{* *} \mathrm{p}<0.01$.

Based on linear probability model with ZIP codes fixed effects. Other control variables include year indicators, patient demographics (5-year age groups, gender, black, Hispanic, other non-white race, urban), 22 comorbid measures, hospital ownership (for-profit, government), teaching status, case mix index, size, occupancy rate, system membership, and Herfindahl index.

Complete regression results are included in Appendix Table 1. 
Table 4. Regression-adjusted percentage point changes in outcomes relative to patients in communities that experienced no ED closure, based on Models 2 and 3 specifications

\begin{tabular}{|c|c|c|c|c|c|c|}
\hline & \multicolumn{3}{|c|}{ Treatments } & \multicolumn{3}{|c|}{ Outcomes } \\
\hline Coefficient $[95 \% \mathrm{Cl}]$ & cath/PCl & $\frac{\text { thrombolytic }}{\underline{\text { therapy }}}$ & $\underline{\mathrm{CABG}}$ & $\frac{30-\text { day }}{\text { mortality }}$ & $\frac{\text { 90-day }}{\text { mortality }}$ & $\frac{1 \text {-year }}{\text { mortality }}$ \\
\hline \multicolumn{7}{|c|}{ Communities with no increase in driving to ED (Reference group) } \\
\hline After driving time increased by $<10 \mathrm{~min}$ & $\begin{array}{l}1.99 * * \\
{[0.49,3.49]}\end{array}$ & $\begin{array}{l}-0.27 \\
{[-0.62,0.09]}\end{array}$ & $\begin{array}{l}0.15 \\
{[-0.40,0.70]}\end{array}$ & $\begin{array}{l}0.00 \\
{[-0.68,0.69]}\end{array}$ & $\begin{array}{l}0.04 \\
{[-0.70,0.78]}\end{array}$ & $\begin{array}{l}-0.26 \\
{[-1.07,0.54]}\end{array}$ \\
\hline After driving time increased by $10-<30 \mathrm{~min}$ & $\begin{array}{l}2.37^{\star \star} \\
{[0.61,4.13]}\end{array}$ & $\begin{array}{l}-0.74^{\star} \\
{[-1.34,-0.15]}\end{array}$ & $\begin{array}{l}0.36 \\
{[-0.27,1.00]}\end{array}$ & $\begin{array}{l}0.72 \\
{[-0.34,1.77]}\end{array}$ & $\begin{array}{l}1.60 \star \star \\
{[0.53,2.67]}\end{array}$ & $\begin{array}{l}2.05^{\star \star} \\
{[0.96,3.14]}\end{array}$ \\
\hline After driving time increased by $>=30 \mathrm{~min}$ & $\begin{array}{l}2.67 \\
{[-3.42,8.76]}\end{array}$ & $\begin{array}{l}0.12 \\
{[-1.25,1.48]}\end{array}$ & $\begin{array}{l}1.82+ \\
{[-0.02,3.65]}\end{array}$ & $\begin{array}{l}2.49+ \\
{[-0.26,5.24]}\end{array}$ & $\begin{array}{l}6.58^{\star \star} \\
{[2.49,10.68]}\end{array}$ & $\begin{array}{l}6.52^{\star \star} \\
{[1.69,11.35]}\end{array}$ \\
\hline Control for access & Yes & Yes & Yes & Yes & Yes & Yes \\
\hline Control for treatment & NA & NA & NA & Yes & Yes & Yes \\
\hline $\mathrm{N}$ & 1350367 & 1350367 & 1350367 & 1350367 & 1350367 & 1350367 \\
\hline
\end{tabular}

* Driving time to nearest ED Based on Google map queries

${ }^{*}$ Coefficients represent differences in percentage point compared to the reference group.

Significant at $+p<0.10{ }^{*} p<0.05 * * p<0.01$.

Based on linear probability model with ZIP codes fixed effects. Other control variables include year indicators, patient demographics (5-year age groups, gender, black, Hispanic, other non-white race, urban), 22 comorbid measures, hospital ownership (for-profit, government), teaching status, case mix index, size, occupancy rate, system membership, and Herfindahl index. 
Table 5. Regression-adjusted percentage point changes in mortality relative to patients in communities that experienced no ED closure, stratified by admitting hospital's PCI capacity

\begin{tabular}{|c|c|c|c|c|c|c|}
\hline \multirow[b]{2}{*}{ coefficient [95\% confidence interval] } & \multicolumn{3}{|c|}{$\begin{array}{c}\text { Among patients who were admitted to } \\
\text { non-PCI hospitals }\end{array}$} & \multicolumn{3}{|c|}{$\begin{array}{c}\text { Among patients who were admitted to } \\
\text { PCI hospitals }\end{array}$} \\
\hline & $\frac{30 \text {-day }}{\text { mortality }}$ & $\begin{array}{l}\text { 90-day } \\
\text { mortality }\end{array}$ & $\underline{\underline{1-y e a r}}$ & $\begin{array}{l}\text { 30-day } \\
\text { mortality }\end{array}$ & $\begin{array}{l}\text { 90-day } \\
\text { mortality }\end{array}$ & $\frac{1 \text {-year }}{\text { mortality }}$ \\
\hline \multicolumn{7}{|c|}{ Communities with no increase in driving to to ED (Reference group) } \\
\hline (base rate in reference group) & $(19 \%)$ & $(26 \%)$ & $(38 \%)$ & $(15 \%)$ & $(21 \%)$ & $(30 \%)$ \\
\hline \multirow[t]{2}{*}{ After driving time increased by $<10 \mathrm{~min}$} & -0.81 & -0.63 & -1.38 & 0.16 & 0.21 & 0.04 \\
\hline & {$[-2.83,1.20]$} & {$[-2.79,1.54]$} & {$[-3.43,0.68]$} & {$[-0.59,0.90]$} & {$[-0.58,1.01]$} & {$[-0.87,0.94]$} \\
\hline \multirow[t]{2}{*}{ After driving time increased by $10-<30 \mathrm{~min}$} & 0.23 & 0.65 & 0.75 & 0.66 & $1.81^{\star \star}$ & $2.46^{\star \star}$ \\
\hline & {$[-1.95,2.42]$} & {$[-1.56,2.87]$} & {$[-1.49,2.98]$} & {$[-0.70,2.03]$} & {$[0.46,3.15]$} & {$[0.98,3.94]$} \\
\hline \multirow[t]{2}{*}{ After driving time increased by $>=30 \mathrm{~min}$} & 2.15 & $7.17^{\star}$ & $7.83^{\star}$ & 1.59 & $4.28^{\star}$ & 2.82 \\
\hline & {$[-2.69,6.98]$} & {$[0.38,13.97]$} & {$[1.40,14.26]$} & {$[-2.64,5.82]$} & {$[0.27,8.29]$} & {$[-2.30,7.95]$} \\
\hline Control for access & Yes & Yes & Yes & yes & yes & yes \\
\hline Control for treatment & Yes & Yes & Yes & yes & yes & yes \\
\hline $\mathrm{N}$ & 247531 & 247531 & 247531 & 1102836 & 1102836 & 1102836 \\
\hline
\end{tabular}

* Driving time to nearest ED Based on Google map queries

** Coefficients represent differences in percentage point compared to the reference group.

Significant at $+p<0.10{ }^{*} p<0.05 * k p<0.01$.

Model specification is the same as Model 3 reported in Table 4 
Appendix Table 1. Model 1 Complete Regression Results

\begin{tabular}{|c|c|c|c|c|c|c|c|c|c|}
\hline \multirow[b]{2}{*}{ Coefficient (SE) in percentage point } & \multicolumn{3}{|c|}{ Access (admitted hospital has:) } & \multicolumn{3}{|c|}{ Treatment } & \multicolumn{3}{|c|}{ Outcomes } \\
\hline & \multicolumn{3}{|c|}{ cardiac care } & \multicolumn{3}{|c|}{ thrombolytic } & $\frac{\text { 30-day }}{\text { mortality }}$ & $\frac{90 \text {-day }}{\text { mortality }}$ & $\frac{1 \text {-year }}{\text { mortality }}$ \\
\hline \multicolumn{10}{|c|}{ Commuinties with no increase in driving to to ED (Reference group) } \\
\hline After driving time increased by $<10 \mathrm{~min}$ & $-3.61 * *$ & $-6.62 * *$ & $-7.06 * *$ & 0.07 & -0.21 & -0.30 & -0.17 & -0.16 & -0.53 \\
\hline & {$[-5.92,-1.30]$} & {$[-10.21,-3.0$} & $4[-11.09,-3.04]$ & {$[-1.35,1.49]$} & {$[-0.57,0.16]$} & {$[-0.87,0.27]$} & {$[-0.85,0.51]$} & {$[-0.91,0.58]$} & {$[-1.34,0.29]$} \\
\hline After driving time increased by $10-<30 \mathrm{~min}$ & $-6.08 * *$ & $-9.54 * *$ & $-6.75 * *$ & -0.05 & $-0.69 *$ & -0.07 & 0.51 & $1.36^{*}$ & $1.76^{* *}$ \\
\hline After driving time increased by $>=30 \mathrm{~min}$ & 0.08 & $-18.64 * *$ & -5.91 & 1.53 & 0.14 & 1.44 & 2.17 & $6.20 * *$ & $6.00^{*}$ \\
\hline & {$[-3.52,3.68]$} & {$[-30.15,-7.1$} & $2[-13.00,1.17]$ & {$[-5.30,8.36]$} & {$[-1.23,1.52]$} & {$[-0.45,3.32]$} & {$[-0.93,5.27]$} & {$[1.97,10.43]$} & {$[0.78,11.23]$} \\
\hline Patient characteristics & & & & & & & & & \\
\hline Female & $-0.27^{* *}$ & $-0.20 * *$ & $-0.27 * *$ & $-3.11 * *$ & $-0.07 * *$ & $-2.03 * *$ & $0.25^{* *}$ & $0.21 * *$ & $-0.33 * *$ \\
\hline & {$[-0.36,-0.18]$} & {$[-0.32,-0.08$} & {$[-0.37,-0.18]$} & {$[-3.26,-2.96]$} & {$[-0.12,-0.03]$} & {$[-2.12,-1.93]$} & {$[0.13,0.38]$} & {$[0.06,0.36]$} & {$[-0.49,-0.17]$} \\
\hline Black & $-0.79 * *$ & $-0.84 * *$ & $-0.87^{* *}$ & $-4.37 * *$ & $-0.35^{* *}$ & $-1.66 * *$ & $-0.73 * *$ & -0.21 & $0.96 * *$ \\
\hline & {$[-1.08,-0.51]$} & {$[-1.24,-0.43]$} & {$[-1.28,-0.47]$} & {$[-4.82,-3.92]$} & {$[-0.44,-0.26]$} & {$[-1.84,-1.48]$} & {$[-1.01,-0.45]$} & ]$[-0.52,0.10]$ & {$[0.62,1.30]$} \\
\hline Reside in urban community & $3.13^{* *}$ & 0.04 & 1.11 & $1.15^{*}$ & -0.04 & -0.25 & 0.05 & 0.14 & -0.10 \\
\hline & {$[1.54,4.73]$} & {$[-2.10,2.19]$} & {$[-0.28,2.50]$} & {$[0.26,2.04]$} & {$[-0.25,0.16]$} & {$[-0.59,0.08]$} & {$[-0.41,0.51]$} & {$[-0.33,0.61]$} & {$[-0.65,0.45]$} \\
\hline age $70-74$ & -0.04 & 0.00 & -0.04 & $-3.29 * *$ & $-0.32 * *$ & $-0.50 * *$ & $1.83^{* *}$ & $2.52 * *$ & $3.75^{* *}$ \\
\hline & {$[-0.18,0.09]$} & {$[-0.18,0.19]$} & {$[-0.19,0.11]$} & {$[-3.52,-3.06]$} & {$[-0.41,-0.23]$} & {$[-0.67,-0.34]$} & {$[1.66,1.99]$} & {$[2.33,2.71]$} & {$[3.54,3.96]$} \\
\hline age $75-79$ & $-0.26 * *$ & -0.12 & $-0.32 * *$ & $-8.12 * *$ & $-0.69 * *$ & $-1.41 * *$ & $4.48^{* *}$ & $6.18^{* *}$ & $8.94 * *$ \\
\hline & {$[-0.41,-0.12]$} & {$[-0.31,0.07]$} & {$[-0.48,-0.16]$} & {$[-8.38,-7.87]$} & ]$[-0.78,-0.60]$ & {$[-1.58,-1.24]$} & {$[4.31,4.66]$} & {$[5.98,6.37]$} & {$[8.72,9.16]$} \\
\hline age $80-84$ & $-0.57^{* *}$ & $-0.39 * *$ & $-0.56^{* *}$ & $-16.31 * *$ & $-1.09 * *$ & $-3.57 * *$ & $7.91^{* *}$ & $10.87^{* *}$ & $15.72^{* *}$ \\
\hline & {$[-0.72,-0.43]$} & {$[-0.59,-0.19]$} & {$[-0.73,-0.40]$} & {$[-16.64,-15$.} & $c[-1.18,-0.99]$ & {$[-3.74,-3.39]$} & {$[7.72,8.10]$} & {$[10.66,11.08$} & $8[15.49,15.96]$ \\
\hline age $85+$ & $-1.04^{* *}$ & $-0.49 * *$ & $-0.95 * *$ & $-35.47 * *$ & $-1.63 * *$ & $-6.62 * *$ & $15.37^{* *}$ & $20.96 * *$ & $29.63 * *$ \\
\hline & {$[-1.21,-0.87]$} & {$[-0.72,-0.26]$} & {$[-1.13,-0.76]$} & {$[-36.07,-34.8$} & $\varepsilon[-1.74,-1.52]$ & {$[-6.86,-6.38]$} & {$[15.17,15.57$} & $7[20.74,21.18$ & $8[29.39,29.87]$ \\
\hline Peripheral vascular disease & $0.35 * *$ & $0.26^{*}$ & 0.12 & $1.20 * *$ & $-0.22 * *$ & $-0.13+$ & $-0.47^{* *}$ & -0.04 & $1.49 * *$ \\
\hline & {$[0.19,0.51]$} & {$[0.05,0.47]$} & {$[-0.05,0.30]$} & {$[0.91,1.48]$} & {$[-0.30,-0.15]$} & {$[-0.28,0.02]$} & {$[-0.69,-0.26]$} & {$[-0.28,0.21]$} & {$[1.21,1.77]$} \\
\hline Pulmonary circulation disorders & $0.43^{* *}$ & $-0.80 * *$ & $-0.70 * *$ & $-5.52 * *$ & $-0.28 * *$ & $-1.63 * *$ & 0.25 & $1.78^{* *}$ & $4.23 * *$ \\
\hline & {$[0.16,0.71]$} & {$[-1.20,-0.41]$} & {$[-1.02,-0.38]$} & {$[-6.02,-5.02]$} & {$[-0.37,-0.19]$} & {$[-1.83,-1.43]$} & {$[-0.14,0.64]$} & {$[1.33,2.23]$} & {$[3.75,4.72]$} \\
\hline Diabetes & $-0.35 * *$ & $-0.23 * *$ & $-0.44 * *$ & $-4.17 * *$ & $-0.65 * *$ & $-0.69 * *$ & $-1.17^{* *}$ & $-0.63 * *$ & $1.62^{* *}$ \\
\hline & {$[-0.45,-0.25]$} & {$[-0.37,-0.10]$} & {$[-0.55,-0.33]$} & {$[-4.34,-3.99]$} & {$[-0.71,-0.60]$} & {$[-0.78,-0.60]$} & {$[-1.30,-1.04]$} & ]$[-0.78,-0.48]$ & {$[1.45,1.79]$} \\
\hline Liver disease & -0.26 & -0.60 & $-1.34 * *$ & $-12.15 * *$ & $-0.66^{* *}$ & $-4.39 * *$ & $6.99 * *$ & $9.67 * *$ & $13.41 * *$ \\
\hline & {$[-0.81,0.29]$} & {$[-1.36,0.16]$} & {$[-1.95,-0.73]$} & {$[-13.19,-11$} & $1[-0.90,-0.43]$ & {$[-4.87,-3.91]$} & {$[6.05,7.93]$} & {$[8.63,10.70]$} & ] $[12.32,14.50]$ \\
\hline Cancer & $-0.30 * *$ & -0.16 & $-0.62 * *$ & $-14.35 * *$ & $-0.61 * *$ & $-3.85^{* *}$ & $11.40 * *$ & $18.64^{* *}$ & $27.36^{* *}$ \\
\hline & {$[-0.53,-0.07]$} & {$[-0.46,0.14]$} & {$[-0.86,-0.37]$} & {$[-14.80,-13$.} & $\varepsilon[-0.71,-0.52]$ & {$[-4.03,-3.67]$} & {$[11.00,11.79$} & $9[18.20,19.07$ & $7[26.92,27.79]$ \\
\hline Dementia & -0.13 & -0.15 & 0.03 & $-9.31 * *$ & $-0.33^{* *}$ & $-0.97 * *$ & $1.86^{* *}$ & $3.49 * *$ & $6.25^{* *}$ \\
\hline & {$[-0.43,0.18]$} & {$[-0.53,0.23]$} & {$[-0.27,0.33]$} & {$[-9.78,-8.85]$} & {$[-0.43,-0.24]$} & {$[-1.10,-0.84]$} & {$[1.41,2.30]$} & {$[3.01,3.97]$} & {$[5.74,6.75]$} \\
\hline Valvular disease & $0.81 * *$ & 0.17 & $-0.22+$ & $-0.40 * *$ & $-0.54 * *$ & $1.62 * *$ & $-1.91 * *$ & $-0.25^{*}$ & $2.64 * *$ \\
\hline & {$[0.61,1.01]$} & {$[-0.17,0.52]$} & {$[-0.43,0.00]$} & {$[-0.66,-0.14]$} & {$[-0.60,-0.47]$} & {$[1.48,1.77]$} & {$[-2.10,-1.72]$} & ]$[-0.47,-0.03]$ & {$[2.39,2.88]$} \\
\hline Hypertension & $0.28^{* *}$ & -0.11 & $-0.26^{* *}$ & $4.60^{* *}$ & $-0.09 * *$ & $-0.69 * *$ & $-8.27 * *$ & $-10.21 * *$ & $-11.60 * *$ \\
\hline & {$[0.17,0.40]$} & {$[-0.27,0.04]$} & {$[-0.37,-0.15]$} & {$[4.43,4.78]$} & {$[-0.14,-0.04]$} & {$[-0.78,-0.60]$} & {$[-8.41,-8.13]$} & ] [-10.36,-10.c & $C[-11.77,-11.44$ \\
\hline Chronic pulmonary disease & $-0.15^{* *}$ & $-0.32 * *$ & $-0.40 * *$ & $-6.16 * *$ & $-0.68 * *$ & $-0.81 * *$ & $0.84^{* *}$ & $2.66^{* *}$ & $6.65^{* *}$ \\
\hline & {$[-0.27,-0.04]$} & {$[-0.47,-0.18$} & ] $[-0.51,-0.29]$ & {$[-6.37,-5.95]$} & {$[-0.73,-0.62]$} & {$[-0.91,-0.71]$} & {$[0.69,1.00]$} & {$[2.48,2.84]$} & {$[6.45,6.85]$} \\
\hline Rheumatoid arthritis/collagen vascular & 0.06 & -0.12 & -0.24 & $-0.77 * *$ & 0.00 & $-1.71 * *$ & $-1.83 * *$ & $-1.43 * *$ & 0.08 \\
\hline & {$[-0.22,0.34]$} & {$[-0.50,0.26]$} & {$[-0.54,0.06]$} & {$[-1.25,-0.28]$} & {$[-0.16,0.16]$} & {$[-1.94,-1.47]$} & {$[-2.22,-1.43]$} & ]$[-1.89,-0.97]$ & {$[-0.44,0.60]$} \\
\hline Coagulation deficiency & $0.39 * *$ & $0.86^{* *}$ & $1.11^{* *}$ & 0.27 & $-0.44 * *$ & $10.91 * *$ & $3.43^{* *}$ & $4.36 * *$ & $4.77 * *$ \\
\hline & {$[0.14,0.63]$} & {$[0.49,1.24]$} & {$[0.81,1.41]$} & {$[-0.19,0.73]$} & {$[-0.54,-0.34]$} & {$[10.38,11.44]$} & {$[3.02,3.85]$} & {$[3.92,4.81]$} & {$[4.30,5.24]$} \\
\hline Obesity & $0.39 * *$ & 0.27 & 0.12 & $3.81^{* *}$ & $-0.14^{*}$ & $1.47^{* *}$ & $-2.82 * *$ & $-3.79 * *$ & $-5.18^{* *}$ \\
\hline & {$[0.15,0.63]$} & {$[-0.06,0.61]$} & {$[-0.15,0.39]$} & {$[3.43,4.19]$} & {$[-0.27,-0.01]$} & {$[1.20,1.75]$} & {$[-3.04,-2.59]$} & ]$[-4.06,-3.53]$ & {$[-5.50,-4.86]$} \\
\hline Substance abuse & 0.05 & 0.05 & 0.04 & $-3.40 * *$ & $-0.43^{* *}$ & -0.34 & $-1.58 * *$ & $-1.72 * *$ & $-0.99 * *$ \\
\hline & {$[-0.34,0.45]$} & {$[-0.46,0.57]$} & {$[-0.40,0.48]$} & {$[-4.09,-2.71]$} & {$[-0.62,-0.23]$} & {$[-0.76,0.08]$} & {$[-2.11,-1.06]$} & {$[-2.32,-1.12]$} & {$[-1.67,-0.30]$} \\
\hline Depression & $-0.48 * *$ & -0.27 & $-0.38 * *$ & $-4.23 * *$ & $-0.42 * *$ & $-1.61 * *$ & $-2.02 * *$ & $-1.76^{* *}$ & $-0.47 *$ \\
\hline & {$[-0.71,-0.24]$} & {$[-0.60,0.06]$} & {$[-0.64,-0.12]$} & {$[-4.62,-3.83]$} & {$[-0.53,-0.32]$} & {$[-1.78,-1.45]$} & {$[-2.33,-1.72]$} & ]$[-2.11,-1.40]$ & {$[-0.88,-0.07]$} \\
\hline Psychosis & $-0.67 * *$ & -0.21 & $-0.75^{* *}$ & $-9.13 * *$ & $-0.37 * *$ & $-1.03^{* *}$ & $-1.15^{* *}$ & -0.15 & $2.44 * *$ \\
\hline & {$[-1.08,-0.26]$} & {$[-0.76,0.34]$} & {$[-1.18,-0.32]$} & {$[-9.77,-8.49]$} & {$[-0.55,-0.20]$} & {$[-1.33,-0.72]$} & {$[-1.69,-0.60]$} & ]$[-0.77,0.48]$ & {$[1.75,3.13]$} \\
\hline Hypothyroidism & -0.12 & -0.15 & $-0.17^{*}$ & -0.05 & $-0.13^{* *}$ & $-0.81 * *$ & $-3.75^{* *}$ & $-4.43 * *$ & $-4.55^{* *}$ \\
\hline & {$[-0.28,0.04]$} & {$[-0.36,0.05]$} & {$[-0.32,-0.01]$} & {$[-0.29,0.19]$} & {$[-0.20,-0.05]$} & {$[-0.93,-0.69]$} & {$[-3.95,-3.55]$} & ]$[-4.66,-4.20]$ & {$[-4.80,-4.29]$} \\
\hline Paralysis and other neurological disorder & $-0.34^{* *}$ & $-0.42 * *$ & $-0.50 * *$ & $-12.19 * *$ & $-0.49 * *$ & $-1.85^{* *}$ & $6.91^{* *}$ & $8.44 * *$ & $10.94 * *$ \\
\hline & {$[-0.52,-0.16]$} & {$[-0.66,-0.18]$} & {$[-0.68,-0.31]$} & {$[-12.55,-11.8$} & $\varepsilon[-0.56,-0.41]$ & {$[-1.99,-1.72]$} & {$[6.61,7.21]$} & {$[8.12,8.76]$} & {$[10.60,11.28]$} \\
\hline Chronic Peptic ulcer disease & -0.32 & -0.23 & -0.62 & $-3.68+$ & 0.37 & 0.22 & $-5.26 * *$ & $-4.24 * *$ & $-7.07^{* *}$ \\
\hline & {$[-2.72,2.08]$} & {$[-2.97,2.50]$} & {$[-2.84,1.60]$} & {$[-7.41,0.05]$} & {$[-1.11,1.85]$} & {$[-1.67,2.12]$} & {$[-7.75,-2.77]$} & ]$[-7.34,-1.13]$ & {$[-10.50,-3.65]$} \\
\hline Weight loss & -0.23 & 0.17 & -0.11 & $-12.64 * *$ & $-0.55^{* *}$ & $1.97^{* *}$ & $9.11^{* *}$ & $15.67^{* *}$ & $18.52^{* *}$ \\
\hline & {$[-0.61,0.15]$} & {$[-0.33,0.68]$} & {$[-0.53,0.31]$} & {$[-13.22,-12$.} & $C[-0.65,-0.45]$ & {$[1.63,2.32]$} & {$[8.53,9.70]$} & {$[15.04,16.31$} & $1[17.90,19.13]$ \\
\hline
\end{tabular}


$[-0.10,0.20] \quad[-0.34,0.08][-0.30,0.01] \quad[-4.14,-3.64][-0.56,-0.44] \quad[0.46,0.75] \quad[-4.19,-3.81][-2.97,-2.53][-0.25,0.25]$

Admitted hospital characteristics

for-profit

government hospital

teaching hospital

case mix index

hospital beds (log transformed)

occupancy rate

hospital is part of a system

hosp $\mathrm{HHI}$ within 15 miles

Constant term $\begin{array}{lllllllll}6.04 * * & 1.55 & 2.06+ & 4.20 * * & 0.08 & 0.96 * * & 0.94 * * & 0.91 * * & 0.82 * *\end{array}$

$[4.35,7.74] \quad[-1.29,4.38][-0.03,4.15] \quad[3.20,5.19][-0.07,0.22] \quad[0.66,1.25] \quad[0.65,1.23][0.59,1.23] \quad[0.48,1.16]$

$\begin{array}{lllllllll}-1.65 & 3.10^{*} & -2.17+ & -2.27^{* *} & 0.29 * * & -0.46^{* *} & 0.63^{* *} & 0.88^{* *} & 1.07 * *\end{array}$

$[-3.80,0.50] \quad[0.35,5.84][-4.71,0.36] \quad[-3.37,-1.17][0.10,0.47] \quad[-0.80,-0.13] \quad[0.27,0.99] \quad[0.48,1.28] \quad[0.64,1.49]$

$\begin{array}{lllllllll}-4.26 * * & -0.75 & -3.52 * * & -4.56 * * & 0.06 & -1.28 * * & 1.27 * * & 1.57 * * & 1.92 * *\end{array}$

$[-6.32,-2.20][-3.75,2.24][-5.76,-1.27] \quad[-5.66,-3.46][-0.05,0.17] \quad[-1.61,-0.95] \quad[0.97,1.57] \quad[1.22,1.92] \quad[1.53,2.32]$

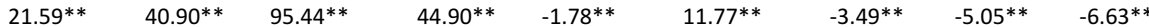

$[18.41,24.77][35.92,45.88[91.26,99.62][42.90,46.91[-2.04,-1.51] \quad[11.16,12.38][-4.05,-2.93][-5.69,-4.41][-7.33,-5.92]$

$\begin{array}{lllllllll}23.05 * * & 22.53 * * & 20.97 * * & 10.85 * * & -0.03 & 1.69 * * & -0.48 * * & -0.75 * * & -1.19 * *\end{array}$

$[21.84,24.26][20.91,24.15[19.60,22.34][10.24,11.47[-0.12,0.06] \quad[1.51,1.88] \quad[-0.68,-0.28][-0.97,-0.53][-1.43,-0.94]$

$\begin{array}{lllllllll}42.56 * * & 26.71 * * & 28.78 * * & 19.40 * * & -0.08 & 1.83 * * & -2.87 * * & -3.31 * * & -3.64 * *\end{array}$

$[38.31,46.81][20.66,32.77[24.21,33.35] \quad[17.18,21.62[-0.50,0.33] \quad[1.22,2.45] \quad[-3.57,-2.18][-4.09,-2.53][-4.50,-2.78]$

$\begin{array}{lllllllll}-1.03+ & -1.13 & -0.62 & -0.33 & -0.20 * * & -0.06 & -0.18+ & -0.13 & -0.08\end{array}$

$[-2.07,0.01] \quad[-2.74,0.47][-1.93,0.70] \quad[-0.93,0.26][-0.30,-0.10] \quad[-0.23,0.11] \quad[-0.37,0.01][-0.35,0.08][-0.32,0.16]$

$\begin{array}{lllllllll}-5.09 * * & -4.23 & 2.51 & -4.90 * * & 0.33 * & -0.04 & 0.14 & 0.17 & 0.54\end{array}$

$[-8.77,-1.40] \quad[-9.61,1.15][-1.01,6.03] \quad[-6.75,-3.05][0.04,0.63] \quad[-0.55,0.46] \quad[-0.42,0.69][-0.46,0.80][-0.17,1.25]$

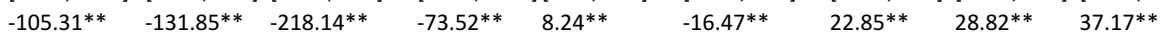

$[-112.53,-98 . C[-140.71,-12[-225.13,-211 .:[-77.28,-69).[[7.64,8.84] \quad[-17.54,-15.39][21.66,24.05[27.48,30.16[35.66,38.68]$

Also included are year indicators

Significant at $+p<0.10{ }^{*} p<0.05{ }^{* *} p<0.01$. 
Appendix Table 2. Complete Regression Results of Table 4

\begin{tabular}{|c|c|c|c|c|c|c|c|}
\hline \multirow[b]{2}{*}{ Coefficient (SE) in percentage point } & \multicolumn{3}{|c|}{ Treatment } & \multicolumn{4}{|c|}{ Outcomes } \\
\hline & \multicolumn{3}{|c|}{ thrombolytic } & $\frac{\text { 30-day }}{\text { mortality }}$ & $\frac{\text { 90-day }}{\text { mortality }}$ & $\frac{1 \text {-year }}{\text { mortality }}$ & $\frac{\text { 30-day }}{\text { readmission }}$ \\
\hline \multicolumn{8}{|c|}{ Commuinties with no increase in driving to to ED (Reference group) } \\
\hline \multirow[t]{2}{*}{ Driving time increased by $<10$ minutes } & $1.99 * *$ & -0.27 & 0.15 & 0.00 & 0.04 & -0.26 & $-1.04 *$ \\
\hline & {$[0.49,3.49]$} & {$[-0.62,0.09]$} & {$[-0.40,0.70]$} & {$[-0.68,0.69]$} & {$[-0.70,0.78]$} & {$[-1.07,0.54]$} & {$[-1.93,-0.14]$} \\
\hline \multirow[t]{2}{*}{ Driving time increased by $10-<30$ minutes } & $2.37^{* *}$ & $-0.74 *$ & 0.36 & 0.72 & $1.60 * *$ & $2.05 * *$ & 1.09 \\
\hline & {$[0.61,4.13]$} & {$[-1.34,-0.15]$} & {$[-0.27,1.00]$} & {$[-0.34,1.77]$} & {$[0.53,2.67]$} & {$[0.96,3.14]$} & {$[-0.92,3.11]$} \\
\hline \multirow[t]{2}{*}{ Driving time increased by $>=30$ minutes } & 2.67 & 0.12 & $1.82+$ & $2.49+$ & $6.58^{* *}$ & $6.52 * *$ & 1.65 \\
\hline & {$[-3.42,8.76]$} & {$[-1.25,1.48]$} & {$[-0.02,3.65]$} & {$[-0.26,5.24]$} & {$[2.49,10.68]$} & {$[1.69,11.35]$} & {$[-4.46,7.76]$} \\
\hline \multicolumn{8}{|l|}{ Patient characteristics } \\
\hline \multirow[t]{2}{*}{ Female } & $-3.01 * *$ & $-0.07 * *$ & $-2.01 * *$ & $-0.20 * *$ & $-0.36 * *$ & $-1.10 * *$ & $5.07 * *$ \\
\hline & {$[-3.16,-2.86]$} & {$[-0.12,-0.03]$} & {$[-2.11,-1.91]$} & {$[-0.33,-0.07$} & {$[-0.50,-0.21]$} & {$[-1.25,-0.94]$} & {$[4.88,5.27]$} \\
\hline \multirow[t]{2}{*}{ Black } & $-4.06 * *$ & $-0.36 * *$ & $-1.61^{* *}$ & $-1.31^{* *}$ & $-0.96 * *$ & -0.05 & -0.13 \\
\hline & {$[-4.49,-3.62]$} & {$[-0.45,-0.27]$} & {$[-1.78,-1.43]$} & {$[-1.59,-1.03$} & {$[-1.27,-0.65]$} & {$[-0.38,0.29]$} & {$[-0.58,0.32]$} \\
\hline \multirow[t]{2}{*}{ Other Race } & $1.27^{* *}$ & -0.00 & $1.30 * *$ & $-1.56 * *$ & $-2.09 * *$ & $-3.21 * *$ & $-2.46 * *$ \\
\hline & {$[0.68,1.85]$} & {$[-0.20,0.19]$} & {$[0.90,1.71]$} & {$[-2.03,-1.08$} & {$[-2.63,-1.55]$} & {$[-3.81,-2.61]$} & {$[-3.26,-1.65]$} \\
\hline Reside in urban community & 0.33 & -0.03 & $-0.32^{*}$ & 0.11 & 0.23 & 0.01 & 0.06 \\
\hline & {$[-0.44,1.10]$} & {$[-0.24,0.17]$} & {$[-0.64,-0.01]$} & {$[-0.35,0.57]$} & {$[-0.23,0.69]$} & {$[-0.54,0.56]$} & {$[-0.62,0.74]$} \\
\hline age $70-74$ & $-3.28 * *$ & $-0.32 * *$ & $-0.50 * *$ & $1.39 * *$ & $1.95^{* *}$ & $3.00 * *$ & $3.05^{* *}$ \\
\hline & {$[-3.50,-3.05]$} & {$[-0.41,-0.23]$} & {$[-0.66,-0.34]$} & {$[1.23,1.55]$} & {$[1.77,2.13]$} & {$[2.79,3.20]$} & {$[2.75,3.34]$} \\
\hline age $75-79$ & $-8.02 * *$ & $-0.69 * *$ & $-1.39 * *$ & $3.40 * *$ & $4.78^{* *}$ & $7.08^{* *}$ & $6.62^{* *}$ \\
\hline & {$[-8.27,-7.77]$} & {$[-0.78,-0.60]$} & {$[-1.55,-1.22]$} & {$[3.23,3.57]$} & {$[4.59,4.98]$} & {$[6.86,7.30]$} & {$[6.31,6.93]$} \\
\hline age $80-84$ & $-16.09 * *$ & $-1.09 * *$ & $-3.53^{* *}$ & $5.72^{* *}$ & $8.05^{* *}$ & $11.97 * *$ & $10.50 * *$ \\
\hline & {$[-16.42,-15.7$} & {$[-1.19,-1.00]$} & {$[-3.71,-3.36]$} & {$[5.53,5.90]$} & {$[7.83,8.27]$} & {$[11.73,12.22$} & $2[10.16,10.84]$ \\
\hline age $85+$ & $-35.10^{* *}$ & $-1.64 * *$ & $-6.56 * *$ & $10.62^{* *}$ & $14.86^{* *}$ & $21.55^{* *}$ & $13.88 * *$ \\
\hline & {$[-35.71,-34.4$} & $\angle[-1.75,-1.53]$ & {$[-6.80,-6.32]$} & {$[10.40,10.8$} & $5[14.61,15.12$ & {$[21.25,21.84$} & $4[13.52,14.24]$ \\
\hline Peripheral vascular disease & $1.10 * *$ & $-0.22^{* *}$ & $-0.14+$ & $-0.33^{* *}$ & 0.15 & $1.72 * *$ & 0.02 \\
\hline & {$[0.82,1.38]$} & {$[-0.30,-0.15]$} & {$[-0.28,0.01]$} & {$[-0.54,-0.12$} & {$[-0.09,0.39]$} & {$[1.44,1.99]$} & {$[-0.31,0.35]$} \\
\hline Pulmonary circulation disorders & $-5.49 * *$ & $-0.28 * *$ & $-1.58 * *$ & $-0.51^{* *}$ & $0.81^{* *}$ & $2.94^{* *}$ & $1.76^{* *}$ \\
\hline & {$[-5.99,-4.99]$} & {$[-0.37,-0.19]$} & {$[-1.78,-1.38]$} & {$[-0.89,-0.13$} & {$[0.36,1.25]$} & {$[2.46,3.41]$} & {$[1.23,2.29]$} \\
\hline Diabetes & $-4.02 * *$ & $-0.66 * *$ & $-0.66 * *$ & $-1.71^{* *}$ & $-1.34^{* *}$ & $0.66 * *$ & $2.05^{* *}$ \\
\hline & {$[-4.20,-3.85]$} & {$[-0.71,-0.60]$} & {$[-0.75,-0.58]$} & {$[-1.85,-1.58$} & {$[-1.49,-1.19]$} & {$[0.50,0.83]$} & {$[1.84,2.25]$} \\
\hline Renal failure & $-12.01^{* *}$ & $-0.32 * *$ & $-1.31^{* *}$ & $4.52^{* *}$ & $7.29 * *$ & $10.45^{* *}$ & $4.50 * *$ \\
\hline & {$[-12.32,-11]$.} & ; $[-0.37,-0.27]$ & {$[-1.43,-1.18]$} & {$[4.31,4.74]$} & {$[7.05,7.54]$} & {$[10.19,10.71$} & $1[4.19,4.80]$ \\
\hline Liver disease & $-11.88^{* *}$ & $-0.68 * *$ & $-4.30 * *$ & $5.31^{* *}$ & $7.53 * *$ & $10.55^{* *}$ & $2.30 * *$ \\
\hline & {$[-12.91,-10 . \varepsilon$} & $\varepsilon[-0.91,-0.44]$ & {$[-4.78,-3.82]$} & {$[4.38,6.25]$} & {$[6.52,8.55]$} & {$[9.50,11.61]$} & {$[0.99,3.61]$} \\
\hline Cancer & $-14.19 * *$ & $-0.62 * *$ & $-3.81 * *$ & $9.44 * *$ & $16.14 * *$ & $24.03 * *$ & $-0.59 *$ \\
\hline & {$[-14.64,-13]$.} & {$[-0.71,-0.53]$} & {$[-3.99,-3.63]$} & {$[9.05,9.83]$} & {$[15.72,16.57$} & $7[23.61,24.45$ & $5[-1.10,-0.08]$ \\
\hline Dementia & $-9.29 * *$ & $-0.33^{* *}$ & $-0.97 * *$ & $0.62 * *$ & $1.91 * *$ & $4.16 * *$ & $0.51+$ \\
\hline & {$[-9.76,-8.82]$} & {$[-0.43,-0.24]$} & {$[-1.10,-0.84]$} & {$[0.18,1.07]$} & {$[1.43,2.38]$} & {$[3.66,4.65]$} & {$[-0.05,1.08]$} \\
\hline Valvular disease & $-0.53 * *$ & $-0.54 * *$ & $1.64^{* *}$ & $-1.93^{* *}$ & $-0.30 * *$ & $2.58^{* *}$ & $1.57^{* *}$ \\
\hline & {$[-0.79,-0.28]$} & {$[-0.60,-0.47]$} & {$[1.49,1.79]$} & {$[-2.11,-1.74$} & {$[-0.52,-0.09]$} & {$[2.35,2.82]$} & {$[1.30,1.84]$} \\
\hline Hypertension & $4.59 * *$ & $-0.10 * *$ & $-0.68 * *$ & $-7.70 * *$ & $-9.46 * *$ & $-10.64 * *$ & $-5.23 * *$ \\
\hline & {$[4.42,4.76]$} & {$[-0.14,-0.05]$} & {$[-0.77,-0.59]$} & {$[-7.84,-7.56$} & ] $[-9.61,-9.30]$ & {$[-10.81,-10.4$} & $\angle[-5.44,-5.02]$ \\
\hline Chronic pulmonary disease & $-6.06 * *$ & $-0.68 * *$ & $-0.79 * *$ & 0.03 & $1.61^{* *}$ & $5.25 * *$ & $3.36 * *$ \\
\hline & {$[-6.27,-5.85]$} & {$[-0.74,-0.62]$} & {$[-0.89,-0.69]$} & {$[-0.13,0.19]$} & {$[1.43,1.78]$} & {$[5.05,5.44]$} & {$[3.12,3.59]$} \\
\hline Rheumatoid arthritis/collagen vascular & $-0.74 * *$ & -0.00 & $-1.69 * *$ & $-1.97 * *$ & $-1.60 * *$ & -0.17 & $0.61+$ \\
\hline & {$[-1.22,-0.26]$} & {$[-0.16,0.16]$} & {$[-1.92,-1.46]$} & {$[-2.36,-1.58$} & {$[-2.05,-1.15]$} & {$[-0.67,0.34]$} & {$[-0.06,1.27]$} \\
\hline Coagulation deficiency & 0.01 & $-0.43^{* *}$ & $10.84^{* *}$ & $3.76^{* *}$ & $4.66^{* *}$ & $5.30 * *$ & $3.14^{* *}$ \\
\hline & {$[-0.44,0.46]$} & {$[-0.53,-0.33]$} & {$[10.31,11.36]$} & {$[3.35,4.16]$} & {$[4.23,5.10]$} & {$[4.86,5.75]$} & {$[2.62,3.66]$} \\
\hline Obesity & $3.71 * *$ & $-0.14^{*}$ & $1.47^{* *}$ & $-2.29 * *$ & $-3.13^{* *}$ & $-4.30 * *$ & $-1.17^{* *}$ \\
\hline & {$[3.34,4.08]$} & {$[-0.27,-0.01]$} & {$[1.19,1.74]$} & {$[-2.51,-2.07$} & ]$[-3.39,-2.87]$ & {$[-4.62,-3.98]$} & {$[-1.61,-0.72]$} \\
\hline Substance abuse & $-3.42 * *$ & $-0.43^{* *}$ & -0.34 & $-2.03 * *$ & $-2.31 * *$ & $-1.77^{* *}$ & $4.84^{* *}$ \\
\hline & {$[-4.10,-2.74]$} & {$[-0.62,-0.23]$} & {$[-0.76,0.08]$} & {$[-2.55,-1.52$} & {$[-2.90,-1.72]$} & {$[-2.43,-1.10]$} & {$[3.97,5.70]$} \\
\hline Depression & $-4.07^{* *}$ & $-0.42 * *$ & $-1.59 * *$ & $-2.60 * *$ & $-2.50 * *$ & $-1.47^{* *}$ & $2.99 * *$ \\
\hline & {$[-4.46,-3.68]$} & {$[-0.53,-0.32]$} & {$[-1.76,-1.42]$} & {$[-2.90,-2.30$} & {$[-2.84,-2.15]$} & {$[-1.86,-1.08]$} & ] $[2.48,3.49]$ \\
\hline Psychosis & $-8.87^{* *}$ & $-0.38^{* *}$ & $-0.98^{* *}$ & $-2.33^{* *}$ & $-1.68 * *$ & 0.42 & $11.94 * *$ \\
\hline & {$[-9.50,-8.24]$} & {$[-0.55,-0.20]$} & {$[-1.28,-0.68]$} & {$[-2.88,-1.79$} & {$[-2.30,-1.06]$} & {$[-0.26,1.10]$} & {$[11.09,12.78]$} \\
\hline Hypothyroidism & 0.00 & $-0.13^{* *}$ & $-0.80 * *$ & $-3.77^{* *}$ & $-4.46 * *$ & $-4.60 * *$ & $-2.24^{* *}$ \\
\hline
\end{tabular}




\begin{tabular}{|c|c|c|c|c|c|c|c|}
\hline \multirow{3}{*}{ Paralysis and other neurological disorder } & {$[-0.24,0.24]$} & {$[-0.20,-0.05]$} & {$[-0.91,-0.68]$} & \multicolumn{4}{|c|}{$[-3.97,-3.58][-4.68,-4.23][-4.85,-4.35][-2.55,-1.92]$} \\
\hline & $-12.04 * *$ & $-0.49 * *$ & $-1.82 * *$ & $5.29 * *$ & $6.36 * *$ & $8.19 * *$ & $8.81 * *$ \\
\hline & {$[-12.39,-11 . \epsilon$} & $\in[-0.57,-0.42]$ & {$[-1.96,-1.69]$} & {$[5.00,5.59]$} & {$[6.05,6.67]$} & {$[7.85,8.52]$} & {$[8.40,9.22]$} \\
\hline \multirow[t]{2}{*}{ Chronic Peptic ulcer disease } & $-3.52+$ & 0.36 & 0.26 & $-5.72 * *$ & $-4.82^{* *}$ & $-7.82^{* *}$ & -3.17 \\
\hline & {$[-7.15,0.12]$} & {$[-1.11,1.84]$} & {$[-1.62,2.15]$} & {$[-8.16,-3.27]$} & {$[-7.88,-1.76]$} & ]$[-11 \cdot 21,-4.4 \vdots$ & $\equiv[-7.83,1.50]$ \\
\hline \multirow[t]{2}{*}{ Weight loss } & $-12.57^{* *}$ & $-0.55^{* *}$ & $1.98 * *$ & $7.54^{* *}$ & $13.61^{* *}$ & $15.84^{* *}$ & $13.01 * *$ \\
\hline & {$[-13.16,-11 . c$} & {$[-0.65,-0.46]$} & {$[1.63,2.33]$} & {$[6.96,8.12]$} & {$[12.99,14.23$} & $3[15.24,16.45$ & $5[12.29,13.74]$ \\
\hline \multirow[t]{2}{*}{ Fluid and electrolyte disorders } & $-9.35 * *$ & $-0.61^{* *}$ & $1.12^{* *}$ & $8.25^{* *}$ & $9.90 * *$ & $10.34^{* *}$ & $7.78^{* *}$ \\
\hline & {$[-9.61,-9.09]$} & {$[-0.67,-0.56]$} & {$[1.00,1.25]$} & {$[8.05,8.44]$} & {$[9.69,10.11]$} & {$[10.12,10.57$} & $7[7.53,8.04]$ \\
\hline \multirow[t]{2}{*}{ Anemia (blood loss and deficiency) } & $-3.88 * *$ & $-0.50 * *$ & $0.62^{* *}$ & $-4.49 * *$ & $-3.39 * *$ & $-0.84 * *$ & $1.32 * *$ \\
\hline & {$[-4.12,-3.63]$} & {$[-0.56,-0.44]$} & {$[0.47,0.76]$} & {$[-4.68,-4.30]$} & {$[[-3.61,-3.17]$} & {$[[-1.09,-0.59]$} & ] $[1.02,1.61]$ \\
\hline \multicolumn{8}{|l|}{ Admitted hospital characteristics } \\
\hline \multirow[t]{2}{*}{ for-profit } & $2.61 * *$ & 0.09 & $0.83^{* *}$ & $1.36^{* *}$ & $1.46^{* *}$ & $1.54^{* *}$ & $1.07^{* *}$ \\
\hline & {$[1.80,3.42]$} & {$[-0.05,0.24]$} & {$[0.57,1.09]$} & {$[1.07,1.66]$} & {$[1.13,1.79]$} & {$[1.19,1.90]$} & {$[0.61,1.52]$} \\
\hline \multirow[t]{2}{*}{ government hospital } & $-1.64 * *$ & $0.26 * *$ & $-0.33^{*}$ & $0.39 *$ & $0.57^{* *}$ & $0.67^{* *}$ & 0.43 \\
\hline & {$[-2.47,-0.81]$} & {$[0.08,0.44]$} & {$[-0.58,-0.07]$} & {$[0.03,0.75]$} & {$[0.17,0.98]$} & {$[0.25,1.10]$} & {$[-0.11,0.98]$} \\
\hline \multirow[t]{2}{*}{ teaching hospital } & $-3.13 * *$ & 0.03 & $-1.06^{* *}$ & $0.78 * *$ & $0.94 * *$ & $1.09 * *$ & $0.94 * *$ \\
\hline & {$[-3.95,-2.31]$} & {$[-0.08,0.14]$} & {$[-1.34,-0.77]$} & {$[0.47,1.09]$} & {$[0.59,1.28]$} & {$[0.71,1.47]$} & {$[0.44,1.45]$} \\
\hline \multirow[t]{2}{*}{ case mix index } & $25.16 * *$ & $-0.86 * *$ & $5.65 * *$ & $0.76^{*}$ & 0.57 & $0.72+$ & $-2.96 * *$ \\
\hline & {$[23.42,26.89$} & $9[-1.13,-0.59]$ & {$[5.03,6.26]$} & {$[0.15,1.38]$} & {$[-0.12,1.25]$} & {$[-0.03,1.47]$} & {$[-3.86,-2.06]$} \\
\hline \multirow[t]{2}{*}{ hospital beds (log transformed) } & $2.57 * *$ & $0.13^{* *}$ & $0.36^{* *}$ & $0.22^{*}$ & 0.19 & 0.06 & $-0.36^{*}$ \\
\hline & {$[2.04,3.10]$} & {$[0.03,0.24]$} & {$[0.18,0.54]$} & {$[0.00,0.44]$} & {$[-0.06,0.43]$} & {$[-0.21,0.32]$} & {$[-0.70,-0.02]$} \\
\hline \multirow[t]{2}{*}{ occupancy rate } & $5.83^{* *}$ & 0.14 & 0.01 & $-1.55^{* *}$ & $-1.54^{* *}$ & $-1.34^{* *}$ & $-1.07+$ \\
\hline & {$[4.09,7.57]$} & {$[-0.28,0.56]$} & {$[-0.52,0.54]$} & {$[-2.29,-0.82]$} & {$[-2.36,-0.73]$} & {$[-2.23,-0.45]$} & {$[-2.19,0.06]$} \\
\hline \multirow[t]{2}{*}{ hospital is part of a system } & -0.01 & $-0.21 * *$ & -0.02 & $-0.19+$ & -0.16 & -0.12 & -0.13 \\
\hline & {$[-0.51,0.49]$} & {$[-0.31,-0.11]$} & {$[-0.17,0.13]$} & {$[-0.39,0.00]$} & {$[-0.38,0.06]$} & {$[-0.36,0.12]$} & {$[-0.44,0.19]$} \\
\hline \multirow[t]{2}{*}{ hosp HHI within 15 miles } & $-4.19 * *$ & $0.37 *$ & -0.21 & -0.44 & $-0.57+$ & -0.42 & $-0.92 *$ \\
\hline & {$[-5.50,-2.87]$} & {$[0.08,0.66]$} & {$[-0.63,0.22]$} & {$[-1.02,0.14]$} & {$[-1.23,0.10]$} & {$[-1.15,0.32]$} & {$[-1.80,-0.05]$} \\
\hline \multicolumn{8}{|l|}{ Admitting hospital cardiac capacity } \\
\hline \multirow[t]{2}{*}{ cardiac care intensive unit available } & $1.29 * *$ & $0.19 *$ & 0.00 & -0.07 & -0.06 & -0.19 & -0.20 \\
\hline & {$[0.63,1.95]$} & {$[0.04,0.33]$} & {$[-0.18,0.18]$} & {$[-0.30,0.16]$} & {$[-0.32,0.20]$} & {$[-0.48,0.09]$} & {$[-0.57,0.17]$} \\
\hline \multirow[t]{2}{*}{ cath lab available } & $20.60 * *$ & 0.07 & -0.07 & $1.90 * *$ & $2.45^{* *}$ & $3.21^{* *}$ & -0.32 \\
\hline & {$[19.65,21.54$} & $4[-0.11,0.25]$ & {$[-0.26,0.12]$} & {$[1.57,2.22]$} & {$[2.08,2.81]$} & {$[2.81,3.61]$} & {$[-0.86,0.22]$} \\
\hline \multirow[t]{2}{*}{ CABG capacity available } & $15.48 * *$ & $-1.06 * *$ & $6.43 * *$ & $1.58 * *$ & $1.76^{* *}$ & $2.42 * *$ & $-1.19 * *$ \\
\hline & {$[14.47,16.49$} & $9[-1.24,-0.87]$ & {$[6.14,6.72]$} & {$[1.29,1.88]$} & {$[1.43,2.08]$} & {$[2.05,2.79]$} & {$[-1.66,-0.72]$} \\
\hline \multicolumn{8}{|l|}{ Treatment received } \\
\hline \multirow[t]{2}{*}{ Received cath/PCI } & & & & $-12.94 * *$ & $-16.73^{* *}$ & $-21.79 * *$ & $-10.40 * *$ \\
\hline & & & & {$[-13.16,-12]$.} & i[-16.98,-16.4 & $\angle[-22.07,-21.5$ & [ $[-10.67,-10.12]$ \\
\hline \multirow[t]{2}{*}{ Received thrombolytic therapy } & & & & -0.10 & $-1.69 * *$ & $-5.13^{* *}$ & -0.41 \\
\hline & & & & {$[-0.57,0.37]$} & {$[-2.19,-1.18]$} & {$[-5.68,-4.58]$} & {$[-1.35,0.53]$} \\
\hline \multirow[t]{2}{*}{ Received CABG } & & & & $-2.88 * *$ & $-2.65^{* *}$ & $-4.92 * *$ & $18.25^{* *}$ \\
\hline & & & & {$[-3.10,-2.67]$} & {$[-2.90,-2.39]$} & {$[-5.21,-4.63]$} & {$[17.69,18.80]$} \\
\hline Constant term & $-16.36 * *$ & $6.26 * *$ & $-2.51 * *$ & $18.24 * *$ & $22.55^{* *}$ & $29.17 * *$ & $37.10 * *$ \\
\hline & {$[-19.68,-13 . c$} & $c[5.60,6.92]$ & {$[-3.68,-1.34]$} & {$[16.87,19.60$} & $0[21.05,24.05$ & $5[27.47,30.86$ & $6[35.00,39.20]$ \\
\hline $\mathrm{N}$ & $1,350,367$ & $1,350,367$ & $1,350,367$ & $1,350,367$ & $1,350,367$ & $1,350,367$ & 996,857 \\
\hline
\end{tabular}

